Department of Economics and Finance

\author{
University of Guelph
}

Discussion Paper 2016-11

\title{
Trade-in and Save: A Two-period Closed-loop Supply Chain Game with Price and Technology Dependent Returns
}

\author{
By: \\ Talat S. Genc and Pietro De Giovanni
}




\title{
Trade-in and Save: A Two-period Closed-loop Supply Chain Game with Price and Technology Dependent Returns
}

\author{
Talat S. Genc* \\ Department of Economics and Finance, University of Guelph, Guelph, Ontario, Canada \\ Department of Economics, Ipek University, Ankara, Turkey \\ Pietro De Giovanni \\ Department of Operations Management, ESSEC Business School, Paris, France
}

July 20, 2016

\begin{abstract}
Consumers evaluate the convenience of changing their products according to the price paid as well as the technology (quality) level. When the consumers wish to capitalize the products residual value, they should return them as early as possible. Accordingly, we develop a model of Closed-loop Supply Chain (CLSC) where consumers seek to gain as much as possible from their returns and the return rate is a function of both price and quality. We model a two-period Stackelberg game to capture the dynamic aspects of a CLSC, where the manufacturer is the channel leader. We investigate who, namely, manufacturer or retailer, should collect the products in the market. Thus, we identify the best CLSC structure to adopt when the return rate is both price- and quality-dependent. Our results demonstrate that it is always worthwhile for companies to collect products and adopt an active return approach for returns. We investigate the effect of retail competition in both forward and backward channels and show the impact of eliminating the double marginalization on market outcomes.
\end{abstract}

Keywords: Closed-Loop Supply Chain, Technology investments, Supply Chain structure, Competition.

\footnotetext{
${ }^{*}$ Corresponding author. Email: tgenc@uoguelph.ca Phone:1.519.824.4120 ext56106
} 


\section{Introduction}

A closed-loop supply chain (CLSC) is a supply chain that integrates forward and backward activities into a unique system and includes, beyond the classical forward activities, several other processes, such as product acquisition, reverse logistics, points of use and disposal, testing, sorting, refurbishing, recovery, recycling, re-marketing, and re-selling (Souza, 2012; Guide and Van Wassenhove, 2009; Fleischmann et al., 2001; Ostlin et al., 2012). The recent trend of research in CLSC highlights three main aspects that should be investigated in that particular framework: 1) who should do the product collection (e.g., Savaskan et al., 2004); 2) which return approach (between value- and waste-stream approaches) firms should undertake (e.g., De Giovanni, 2014); and 3) how competition influences firms' strategies and profits (Savaskan and van Wassenhove, 2006).

The rationale behind the implementation of a CLSC is that production using virgin materials is more expensive than production using recycled materials. Therefore, cost savings and willingness to return the used products establish the benefits of closing the loop (Guide, 2000). Cost savings targets can vary across different industries. For instance, the reuse of returned car engines and parts lead to a $70 \%$ cost savings for Volkswagen (Volkswagen, 2011). Kodak saves $40-60 \%$ of production costs as it manufactures cameras using returned cameras rather than using raw materials (Savaskan et al., 2004). Fleischmann et al. (2002) report that remanufacturing costs at IBM are lower, as much as $80 \%$ lower, than those when buying new parts. Xerox saves $40-65 \%$ of its manufacturing costs by reusing parts, components and materials from returned products (Savaskan et al., 2004). Remanufactured cartridges cost 30\% to $60 \%$ less on a per-copy basis than do non-remanufactured cartridges. TriNet has been purchasing remanufactured toner cartridges and saving $25 \%$ to $60 \%$ in costs over the price of new cartridges within five years (www.stopwaste.com). Interface Inc. is the world's largest provider of commercial carpet tile. It leases carpets instead of selling them to create efficiency in the CLSC. The ownership of on-lease products provides motivations for Interface to close the loop and recover the residual value of these products (Agrawal and Tokay 2010). One question frequently asked in CLSC research is: Which firm should collect the past-sold products to improve both the environmental and the economic performance? In general, manufacturers have economic reasons for performing their backward logistics activities and closing the loop. This is because the residual value of returns increases profits. Therefore, firms need to integrate both forward and backward activities into a unique system (Kenne et al., 2012 ) by accommodating green concepts and managerial practices and integrating both into their conventional models (Andriolo et al., 2015).

Beyond operational and economic motivations, other forces, such as legislation and supplier pressure, can push firms to take part in a CLSC. On the one hand, take-back legislation imposes several constraints on firms to get back their past-sold products (Guide and van Wassenhove, 2009). For instance, extended 
producer responsibility laws regarding the waste treatment and management from electric and electronic equipment (e.g., 2002/96/EC) impose certain minimum collection targets on producers and retailers. Thus, the selection of a proper CLSC structure can substantially help reach these targets (Hammond and Beullens, 2007). Similarly, the end-of-life vehicles directive (e.g., 2000/53/EC) enforces EU car manufacturers to recover the waste within a CLSC and produce new vehicles without hazardous substances. These types of directives also exist in other countries. For example, Japan has implemented a recycling fee program to encourage the public to buy, and manufacturers to design vehicles that are more easily recyclable and thus abide by the Japanese Automobile Recycling Law ${ }^{1}$. However, there are countries in which the legislation is less restrictive for CLSCs. For instance, despite the magnitude of the waste problem posed by end-of-life vehicles, both the Canadian and the US governments have paid little attention to vehicle waste. Until recently, the Canada-wide Action Plan for Extended Producer Responsibility ${ }^{2}$ has defined several constraints for car manufacturers to handle their past-sold products. In sum, legislation restrictions can enforce firms to coordinate their CLSCs, independently of any implied operational efficiency. On the other hand, suppliers can also put substantial pressure on distributors to engage in a CLSC program. Firms need to adopt numerous environmentally oriented practices to become "green" and take part in a CLSC (De Giovanni and Esposito Vinzi, 2012). For example, IBM and Xerox have chosen only green suppliers to integrate and coordinate their forward and backward activities along the chain (e.g., Guide et al., 2003). Thus, firms within a CLSC will select their partners according to both operational (e.g., collection efficiency (Savaskan et al., 2004)) and environmental criteria (e.g., responsible collection (De Giovanni and Zaccour, 2014)).

In reality, the CLSC structure can take several shapes and the collection process can be carried out by firms that are not necessarily manufacturers. Savaskan et al. (2004) explore three different collection options in which the recovery program is initiated either by a manufacturer, by a retailer, or by third-party logistics. They have shown that when a retailer invests in promotions or Green Activity Programs (GAP) and also collects used products, the maximization of both environmental and economic performance is guaranteed. In a similar framework, Savaskan and van Wassenhove (2006) investigate the impact of competition. Also in this case, both the environmental and the economic performance are maximized when a retailer performs the collection process. In the same vein, De Giovanni and Zaccour (2014) extend the Savaskan et al.'s model in a two-period framework to demonstrate the need of studying CLSCs in a dynamic setting. When adding a dynamic component, there is only a small region wherein Savaskan et al.'s findings remain valid. In most of the cases, the collection should be done by a manufacturer. All these papers, however, share a common point: Firms spend efforts and resources to increasing the return rate as much as possible. This approach is

\footnotetext{
${ }^{1}$ Japan For Sustainability, "The Recycling of End-of-Life Vehicles in Japan”, JFS Newsletter No. 50, October 2006. Accessible at www.japanfs.org

${ }^{2}$ Canadian Council of Ministers of the Environment, "Extended Producer Responsibility". Accessible at www.ccme.ca
} 
called value-stream or active return approach. In fact, firms invest in GAP to perform both the return rate (e.g., Savaskan et al., 2003) and the reverse logistics activities.

In comparison to the value stream approach, firms can also undertake an alternative approach for returns, which is called passive return policy or waste stream approach. In this case, firms passively collect all pastsold products by waiting for consumers who voluntarily return products (Ostlin et al., 2012). Under these circumstances, the recovery process is a cost center that receives low quality (Debo et al., 2003). Research on waste stream policy considers the return rate either as an exogenous parameter or as a random variable. For example, Dobos (2003) models the return rate as a constant fraction of the past-sold products, while Minner and Kleber (2001) characterize a return rate as a constant percentage of sales. Atasu et al. (2008a) hypothesize a $100 \%$ return rate while also focusing more on the price and cost differences between new and remanufactured goods. Geyer et al. (2007) highlight the needs to coordinate the return rate with cost savings to properly assess the benefits of a remanufacturing system. Ferrer and Swaminathan (2006) model a twoperiod game wherein a remanufacturer optimally decides price and quantity, while the players never invest in increasing the return rate, which is assumed to be a fixed parameter.

Our first contribution here is to highlight how firms' strategies and profits change when firms move from a passive to an active return policy. Our intuition is that the return rate should be endogenous and companies should undertake specific actions/strategies to change it (Ostlin et al., 2012). In particular, we assume that the return rate depends on both the price as well as the product quality (technology). It is well documented (De Giovanni, 2014) that return residual value decreases over time, thus consumers may want to return it as early as possible to increase their rewards. Similarly, the technology developments substantially influence the consumers' willingness to return. In particular, when technological advancements are not impressive, consumers have a lower willingness to return a product and acquire a new technology. Therefore, we model a return rate as a function of both price and technology level. We then compare the results with a waste return case to analyze how the effect of an endogenous return rate modifies firms' strategies and profits.

The second contribution of this paper is identifying the firm that should collect end-of-use products to enhance both environmental and economic performance. The main problem of coordination in CLSC consists of the identification of a proper incentive scheme that suits the collector (Ferguson and Toktay 2006). Incentive alignment and contractual agreements have been extensively investigated to properly set out various policies (see De Giovanni (2015) and Sluis and De Giovani (2016) for a latest overview). We model a per-unit incentive scheme (Savaskan et al., 2004), which is the most intuitive and effective approach that firms use to coordinate a CLSC (Kumar and Putnam, 2008). In addition, we seek to verify whether the application of a per-return incentive mechanism is efficient in a CLSC where the return rate is price and 
quality dependent. De Giovanni (2015) has shown that a per-return incentive is not efficient in a CLSC when the return rate depends on the GAP efforts only.

The third contribution of this paper is understanding how firms strategies and profits change under a competitive framework. Most of the CLSC literature has unfortunately disregarded the effect of competition, which, in our belief, should be incorporated into any realistic CLSC model. The main contribution in this research stream is presented by Savaskan and van Wassenhove (2006), who model several CLSC structures to show how competition influences firms' strategies and profits. We follow this paper to address the same research questions, but with different assumptions regarding the return rate (which depends on pricing and quality rather than promotional efforts) and the market structure (where we model a two-period game rather than a single-period framework). Our developments offer a substantial contribution to understanding the role of competition within a CLSC on which only a few papers have been written to date. Apart from Savaskan and Van Wassenhove (2006), Majumder and Groenevelt (2001) demonstrate that competition is an essential structure to decrease the collection cost. However, the achievement of coordination in a CLSC where retail competition exists has been shown to provide an infeasible outcome under certain circumstances (e.g., see Chen et al., 2001, Berstein et al., 2002, Federgruen, 2005).

Following these early intuitions, we first consider a benchmark CLSC model where the manufacturer optimally sets the quality investments and the retailer sets the retail price in two periods. Note that the retailer does not participate in enhancing the return rate, so she passively sells products to consumers who visit the store. Next, we contrast the results of the benchmark game with an incentive framework in which the manufacturer provides an economic incentive to the retailer to collect the end-of-use products. This incentive allows the retailer to actively participate in performing the return rate. The results of these two models are then compared with a waste-stream approach, in which both players do nothing to increase the return rate. Finally, the introduction of competition in the downstream provides intuitions on how firms should act when competitors are present.

Insert Figure 1 here

To recapitulate, we explore the CLSC structures that are displayed in Figure 1 and address the following research questions:

- How do firms in a CLSC set their pricing and quality decisions when their return rates depend on both price and technology developments? 
- How do firms' strategies and profits change when they move from a passive to an active return policy?

- Which firm should do the collection of end-of-use products to maximize the overall profits?

- How does competition influence firms' strategies and profits?

The remaining of the paper is structured as follows. Section 2 introduces a two-period model of CLSC.

Sections 3, 4, and 5 propose the solutions for all the models examined, while Section 6 introduces competition in the retail sector. Section 7 briefly concludes the paper and suggests future research directions.

\begin{tabular}{|l|l|}
\hline$t$ & Planning horizon of two periods \\
\hline$\alpha_{t}$ & Market potential in period $t$ \\
\hline$\beta$ & Consumers' sensitivity to price \\
\hline$\theta$ & Consumers' sensitivity to advertising \\
\hline$c_{p}$ & Marginal production cost \\
\hline$\omega$ & Wholesale price per quality \\
\hline$\mu$ & Quality efficiency \\
\hline$\delta$ & Discount factor \\
\hline$\gamma$ & Scaling parameter \\
\hline$c_{c}$ & Collection cost per quality \\
\hline$g$ & Unit collection cost per quality \\
\hline$\phi$ & Payment to consumer per quality \\
\hline$\nu$ & Fee paid by $M$ to $R$ \\
\hline$\Delta$ & $M$ 's marginal residual value per quality \\
\hline$n$ & Number of retailer in the market \\
\hline$T$
\end{tabular}

Table 1. Notations

\section{A two-period model of CLSC}

Table 1 displays all notations we use in the paper. We assume that a CLSC is composed of one manufacturer, firm $M$, and one retailer, firm $R$. Whatever actions these two players undertake, they should be evaluated in a non-static setting as consumers purchase products in a given period, e.g., $t=1$, and they return them after some periods of consumption, e.g., $t=2$. Thus the purchasing and the returning actions are taken in two different instants of time (De Giovanni and Zaccour, 2014). This is the reason why CLSCs should be studied in dynamic settings (e.g., Kenne et al., 2012). Accordingly, we model a two-period game in which the 
firms decide on their optimal strategies to maximize their profits. This formulation has been used in CLSC research because it captures the dynamic interactions without compromising the analytical results (see De Giovanni and Zaccour, 2014; Atasu et al., 2003). Therefore, time matters and it is expressed by $t=1,2$. Consistent with its position in the supply chain, $M$ considers the operational aspects linked to a CLSC with a particular emphasis on the technology developments, which can be expressed, for instance, by the design quality (as in El Ouardighi and Kim, 2011). Thus, $M$ invests in quality efforts, $A_{t}$, whose cost is determined according to the following equation:

$$
C_{t}\left(A_{t}\right)=\mu A_{t}
$$

where $\mu>0$ is the operational efficiency and informs on the marginal impact of each dollar invested in quality on $M$ 's profit function. These investments in quality also generate some production costs. It is well known that the larger the investment in quality, the larger will be the production cost due to trials, larger controls, high quality of raw materials, and employee efforts. Consistent with Nair and Narashiman (2007), we assume a linear production cost function that is expressed as follows:

$$
C_{p_{t}}\left(A_{t}\right)=c_{p} A_{t}
$$

where $c_{p}>0$ is the marginal production cost per unit of quality. Throughout the paper, we assume that $M$ does not directly set the optimal wholesale price. In fact, the wholesale price is a function of quality. Specifically, we assume that $M$ 's wholesale price takes the following form:

$$
p_{M t}\left(A_{t}\right)=\omega A_{t}
$$

where $\omega$ is a positive constant. Indeed, the marginal benefit should satisfy $\omega-c_{p}>0$. The expression in Eq. (??) represents a cost for $R$, who pays $p_{M_{t}}$ to $M$ and then sells the product to consumers. In particular, $R$ optimally chooses the retail prices in both periods, $p_{t}$, and gains a marginal benefit that takes the following form:

$$
b_{R t}\left(p_{t}, A_{t}\right)=p_{t}-\omega A_{t}
$$

$R$ will choose its retail price to guarantee that its cost per unit of sale is covered: $p_{t}-\omega A_{t}>0$. Both firms' strategies, $p_{t}$ and $A_{t}$, contribute to the sales, thus exerting a marketing role that can be summarized in the following demand function:

$$
q_{t}\left(p_{t}, A_{t}\right)=\alpha_{t}-\beta_{t} p_{t}+\theta_{t} A_{t}
$$


where $\alpha_{t}>0$ is the market potential and describes the potential consumers who are interested in purchasing the product during a given period, $\beta_{t}$ is the consumers' sensitivity to price and describes how consumers react to any price increase, and $\theta_{t}$ is the consumers' sensitivity to quality and shows how demand varies any time as $M$ increases his quality efforts by a unit. We assume that the market potential, $\alpha$, changes from a period to another because we seek to distinguish between new consumers who purchase in the second period and first-period consumers who return the product. In contrast, we assume that consumers price responsiveness and quality perception are identical in both periods because the firms sell to the same consumer type. Consequently, $\beta_{t}=\beta$ and $\theta_{t}=\theta$. The demand function in Eq.(??) indicates the relationship between quantity demanded, price, and quality whose trade-offs have been largely investigated in the game theory literature (e.g., Martín-Herrán et al., 2012; El Ouardighi, 2014; De Giovanni, 2011, 2012). For example, Ghosh and Shah (2015) assume exactly the same demand function to investigate the trade-off between pricing and green improvement efforts, in which both have a linear impact on sales. Furthermore, the links among quality, pricing and demand have also been supported by several empirical research that show the existing interactions and interfaces (e.g., Forza and Filippini, 1998; Kaynak, 2003).

Both firms' strategies, $p_{t}$ and $A_{t}$, have important operational implications, as they have a direct impact on the return rate of products. The return rate defines the fraction of consumers who purchase some products in $t=1$ and return some of them in $t=2$. We assume that both strategies have an impact on the return rate according to the following relation:

$$
r\left(p_{1}, A_{1}\right)=\frac{\gamma p_{1}}{A_{1}}
$$

where $\gamma>0$ is a scaling parameter. The interpretation of Eq. (??) is that consumers are highly oriented to purchase the product with the highest possible quality (e.g., a smartphone with the latest technology available), and when a new version with a better quality is launched in the market they wish to buy it. In this case, they know that the value of the return highly depends on the price. Thus, to get back as much as possible, they will have a greater incentive for returning the product, i.e., $\frac{\partial r}{\partial p_{1}}=\frac{\gamma}{A_{1}}>0$. At the same time, they evaluate the product quality before returning it. When the quality, $A_{1}$, is still high even after using the product for one period, the consumers can be reluctant to return it, i.e., $\frac{\partial r}{\partial A_{1}}=-\frac{\gamma p_{1}}{A_{1}^{2}}<0$. Alternatively, the return rate function can be viewed as simply a negative demand that is decreasing in quality and yet increasing in price.

Because the return rate, $r$, is a fraction, one should guarantee that $r \in(0,1)$, while the number of return $q_{1} r$ generates some revenues for firms. In particular, we model two scenarios in which the collection process can be carried out either by $M$ or by $R .^{3}$ When $M$ collects the end-of-use products ( $\mathcal{M}$-scenario), $R$ does not

\footnotetext{
${ }^{3}$ We use the superscript $\mathcal{M}$ to identify the scenario in which $M$ collects and $\mathcal{R}$ to identify the scenario in which $R$ collects.
} 
play any role in the collection process; thus, $M$ retains all marginal benefits from reverse logistics expressed by $\Delta-c_{c}$, where $\Delta>0$ is the marginal returns' residual value, while $c_{c}>0$ is the marginal collection cost. By construction, we impose that $\Delta>c_{c}$. Therefore, in the $\mathcal{M}$-scenario the firms' objective functions read as follows:

$$
\begin{aligned}
& \underset{A_{1}, A_{2}}{\max \Pi_{M}^{\mathcal{M}}}=\underbrace{q_{1}\left(\omega-c_{p}\right) A_{1}-\mu A_{1}}_{M^{\prime} \text { s Forward profit in } t_{1}}+\underbrace{\delta q_{2}\left(\omega-c_{p}\right) A_{2}-\mu A_{2}}_{M^{\prime} \text { s Forward profit in } t_{2}}+\underbrace{\delta r q_{1}\left(\Delta-c_{c}\right) A_{1}}_{M^{\prime} \text { s Backward profit in } t_{2}} \\
& \max _{p_{1}, p_{2}} \Pi_{R}^{\mathcal{M}}=\underbrace{q_{1}\left(p_{1}-\omega A_{1}\right)}_{R^{\prime} \text { s Forward profit in } t_{1}}+\underbrace{\delta q_{2}\left(p_{2}-\omega A_{2}\right)}_{R^{\prime} \text { s Forward profit in } t_{2}}
\end{aligned}
$$

where $\delta>0$ is the discount factor assumed by all firms. Differently, when $R$ collects the end-of-use products, she is fully involved in the reverse logistics process, thus the firms' objective functions are:

$$
\begin{aligned}
\max _{A_{1}, A_{2}} \Pi_{M}^{\mathcal{R}} & =\underbrace{q_{1}\left(\omega-c_{p}\right) A_{1}-\mu A_{1}}_{M^{\prime} \text { s Forward profit in } t_{1}}+\underbrace{\delta q_{2}\left(\omega-c_{p}\right) A_{2}-\mu A_{2}}_{M^{\prime} \text { s Forward profit in } t_{2}}+\underbrace{\delta r q_{1}(\Delta-(1+\nu) g-\phi) A_{1}}_{M^{\prime} \text { s Backward profit in } t_{2}} \\
\max _{p_{1}, p_{2}} \Pi_{R}^{\mathcal{R}} & =\underbrace{q_{1}\left(p_{1}-\omega A_{1}\right)}_{R^{\prime} \text { s Forward profit in } t_{1}}+\underbrace{\delta q_{2}\left(p_{2}-\omega A_{2}\right)}_{R^{\prime} \text { s Forward profit in } t_{2}}+\underbrace{\delta r q_{1} \nu g A_{1}}_{R^{\prime} \text { s Backward profit in } t_{2}}
\end{aligned}
$$

Within the games described in scenarios $\mathcal{M}$ and $\mathcal{R}$, we aim at investigating how firms' strategies and profits change when the collection process is managed by different players, given that the return rate depends on both price and quality decisions. We seek to identify the best suitable CLSC structure to adopt in such a framework. Finally, we also pinpoint the role of competition in CLSCs when more retailers compete for the product sales and collections. In this sense, we can check whether the findings by Savaskan and van Wassenhove (2006) remain valid in our framework. To summarize, with the models proposed in this paper, we wish to verify whether the results obtained in the literature are justifiable when: $i$ ) the return rate does not depend on a firm's promotion efforts (as in Savaskan et al. (2004) and Savaskan and Van Wassenhove (2006)) or green expenditures (as in De Giovanni and Zaccour (2014) and De Giovanni et al. (2015)) but rather on price and quality; ii) the investigated framework consists of two periods.

\section{Model $\mathcal{M}$ - The manufacturer collection case}

In this section, we study a game $($ model- $\mathcal{M})$ in which $M$ collects the end-of-use products, invests in technology (quality) and retains all the operational and economic benefits linked to a CLSC. We assume that $M$ is the channel leader and moves first, and thus it can maximize the sum of its discounted profits while managing both forward (i.e., selling new products to $R$ ) and backward activities (i.e., collecting all end-of-use products 
from the market). $R$ is a follower and maximizes the sum of its discounted profits for two periods while focusing on forward activities (e.g., sales of new products to consumers). In the first period, given that the demand is represented by Eq. (??) and the marginal production cost per quality is $c_{p}$, $M$ chooses his level of technology efforts $A_{t}$ (and hence the wholesale price) to maximize his profits. On the other hand, $R$ optimally sets the retail price $p_{t}$ to maximize her profits. The consumers consume $q_{t}$ amount for a given technology and price. The timing of the subgame perfect Stackelberg game is as follows. In the first stage of period $1, M$ chooses technology $A_{1}$ optimally. In the second stage of the first period, $R$ optimally chooses the retail price $p_{1}$. This period ends here. In period 2 some customers return the used product at the rate $r$ to $M$. Also in period 2, $M$ chooses technology $A_{2}$, and then $R$ follows by choosing the retail price.

Proposition 1: Assuming an interior solution, the firms' subgame perfect equilibrium strategies in the $\mathcal{M}-$ scenario are given by:

$$
\begin{aligned}
p_{1}^{\mathcal{M}} & =\frac{2 \mu(\theta+\beta \omega)+\alpha_{1}\left[\left(c_{p}-\omega\right)(3 \beta \omega-\theta)-\omega \delta \gamma(\Delta-g-\phi)(\theta+\beta \omega)\right]}{2\left[2 \beta\left(\omega-c_{p}\right)(\theta-\omega \beta)+\gamma \delta(\Delta-\phi-g)(\theta-\beta \omega)(\theta+\omega \beta)\right]} \\
q_{1}^{\mathcal{M}} & =\frac{\beta(\theta-\beta \omega)\left[\alpha_{1}\left(\omega \delta \gamma(g-\Delta+\phi)-\omega+c_{p}\right)-2 \mu\right]}{2\left[2 \beta\left(\omega-c_{p}\right)(\theta-\omega \beta)+\gamma \delta(\Delta-\phi-g)(\theta-\beta \omega)(\theta+\omega \beta)\right]} \\
A_{1}^{\mathcal{M}} & =\frac{\beta\left[2 \mu-\alpha_{1}\left(\omega-c_{p}\right)\right]-\alpha_{1} \theta \gamma \delta(\Delta-\phi-g)}{2 \beta\left(\omega-c_{p}\right)(\theta-\omega \beta)+\gamma \delta(\Delta-\phi-g)(\theta-\beta \omega)(\theta+\omega \beta)}
\end{aligned}
$$

in the first period, and

$$
\begin{aligned}
p_{2}^{\mathcal{M}} & =\frac{2 \mu(\theta+\omega \beta)+\alpha_{2}\left(\omega-c_{p}\right)(\theta-3 \omega \beta)}{4 \beta(\theta-\omega \beta)\left(\omega-c_{p}\right)} \\
q_{2}^{\mathcal{M}} & =\frac{2 \mu+\alpha_{2}\left(\omega-c_{p}\right)}{4\left(\omega-c_{p}\right)} \\
A_{2}^{\mathcal{M}} & =\frac{2 \mu-\alpha_{2}\left(\omega-c_{p}\right)}{2\left(\omega-c_{p}\right)(\theta-\omega \beta)}
\end{aligned}
$$

in the second period.

Proof. See the Appendix.

To satisfy the positivity assumptions for these strategies, we need to assume a certain relationship between the model parameters. First, note that all model parameters are non-negative. Clearly, $\Delta-\phi-g>0$ so that the marginal benefit of collection is higher than the marginal cost of collection. Further, $\omega-c_{p}>0$ must hold because the wholesale price always exceeds the unit cost of production for $M$. To have a strictly positive retail price in period 2 , we assume that $\theta \geq 3 \omega \beta$, which is a sufficiency condition. To have a positive quality level $A_{1}$, we assume that $2 \mu>\alpha_{1}\left(\omega-c_{p}\right)+\alpha_{1} \theta \gamma \delta(\Delta-\phi-g) / \beta$. When this condition is satisfied $p_{1}$ and $q_{1}$ directly become positive. To have a positive $A_{2}$, the condition $2 \mu>\alpha_{2}\left(\omega-c_{p}\right)$ should also hold. 
Note that when firms disregard future outcomes in their optimization problems, that is $\delta=0$, the return rate is still positive and equals to:

$$
r_{\delta=0}=\gamma\left[\alpha_{1}\left(\omega-c_{p}\right)(\theta-3 \omega \beta)+2 \mu(\theta+\omega \beta)\right] / 2 \beta\left(2 \mu-\alpha_{1}\left(\omega-c_{p}\right)\right)
$$

Moreover, when the second period market unfolds, firms will mimic their first period decisions that will be different in terms of the market potential, $\alpha$, only. Indeed, if $\alpha_{1}=\alpha_{2}$ then $p_{1}=p_{2}$ and $A_{1}=A_{2}$ in the presence of zero discount factor.

In this model both prices (wholesale and retail) increase in quality, but the collection rate decreases in quality. Interestingly, the higher the marginal rate of benefit to the manufacturer $(\Delta-\phi-g)$, the lower the quality offered in period $1\left(A_{1}\right)$. This result implies lower retail price $\left(p_{1}\right)$ and lower consumption $\left(q_{1}\right)$ as the quality $\left(A_{1}\right)$ decreases. Moreover, the return rate $(r)$ increases in $M$ 's marginal benefit. Also, if $M$ spends more to create a better technology, then it charges a higher (wholesale) price, which in turn will imply a higher retail price. That is, $\partial A_{t} / \partial \mu>0, \partial p_{t} / \partial \mu>0, \partial q_{t} / \partial \mu>0$ in both periods.

Corollary 1: In the absence of backward activities (collection, recycling, and remanufacturing), the unique subgame perfect Stackelberg equilibrium outcomes are

$$
\hat{A}_{t}=\frac{2 \mu-\alpha_{t}\left(\omega-c_{p}\right)}{2\left(\omega-c_{p}\right)(\theta-\omega \beta)}, \hat{p}_{t}=\frac{2 \mu(\theta+\omega \beta)+\alpha_{t}\left(\omega-c_{p}\right)(\theta-3 \omega \beta)}{4 \beta(\theta-\omega \beta)\left(\omega-c_{p}\right)}, \hat{q}_{t}=\frac{2 \mu+\alpha_{t}\left(\omega-c_{p}\right)}{4\left(\omega-c_{p}\right)}, t=1,2 .
$$

\section{Proof. See the Appendix.}

Comparing the results in Proposition 1 to those in Corollary 1, it is clear that the second stage decisions are identical, independently of any backward activity. This finding is due to the model assumptions, as we assume that $M$ does not collect any of the products sold in period 2 and that the game ends there (e.g., see De Giovanni and Zaccour, 2014). However, the decisions in the first period are different. In particular, the quality offered under collection process is lower than the quality offered without collection in the first period, i.e., $A_{1}^{\mathcal{M}}<\hat{A}_{1}$. Further, if the market potentials in the two periods are the same (i.e., $\alpha_{1}=\alpha_{2}$ ), then the quality levels offered in both periods is the same in case of no collection program, that is $\hat{A}_{1}=\hat{A}_{2}$. Nevertheless, with a collection program, $M$ will choose a higher quality in the second period, that is $A_{2}^{\mathcal{M}}>A_{1}^{\mathcal{M}}$. The comparison of the prices, profits, and sales directly follows from comparison of the product quality above.

Corollary 2: Consumers who trade-in and save: i) pay lower prices under the collection program; ii) get a higher quality in the second period.

\section{Proof. See the Appendix.}


Indeed, consumers pay lower price(s) by trading-in their used products. If they are trading up, they may even obtain a better quality product because $A_{2}^{\mathcal{M}}>A_{1}^{\mathcal{M}}$.

When moving from an active return approach that depends on both price and quality as in Eq. (6) to a passive return approach, the following result is obtained.

Proposition 2: If the return function is exogenous, i.e., $r=\gamma$, then the interior, unique subgame perfect Stackelberg equilibrium price, sales, and quality strategies are:

$$
\begin{aligned}
\widetilde{p}_{1}^{\mathcal{M}} & =\frac{2 \mu(\theta+\beta \omega)+\alpha_{1}\left\{(\theta+3 \omega \beta)\left[\left(\omega-c_{p}\right)-\delta \gamma(g-\Delta+\phi)\right]\right\}}{4 \beta(\theta-\beta \omega)\left[\omega-c_{p}+\gamma \delta(\Delta-\phi-g)\right]}, \\
\widetilde{q}_{1}^{\mathcal{M}} & =\frac{2 \mu \alpha_{1}\left(\omega-c_{p}-\delta \gamma(g-\Delta+\phi)\right)}{4 \beta(\theta-\beta \omega)\left[\omega-c_{p}+\gamma \delta(\Delta-\phi-g)\right]} \\
\widetilde{A}_{1}^{\mathcal{M}} & =\frac{2 \mu-\alpha_{1}\left[\omega-c_{p}+\gamma \delta(\Delta-\phi-g)\right]}{2(\theta-\omega \beta)\left[\omega-c_{p}+\gamma \delta(\Delta-\phi-g)\right]}
\end{aligned}
$$

in the first period, and

$$
\begin{aligned}
\widetilde{p}_{2}^{\mathcal{M}} & =\frac{2 \mu(\theta+\omega \beta)+\alpha_{2}\left(\omega-c_{p}\right)(\theta-3 \omega \beta)}{4 \beta(\theta-\omega \beta)\left(\omega-c_{p}\right)} \\
\widetilde{q}_{2}^{\mathcal{M}} & =\frac{2 \mu+\alpha_{2}\left(\omega-c_{p}\right)}{4\left(\omega-c_{p}\right)} \\
\widetilde{A}_{2}^{\mathcal{M}} & =\frac{2 \mu-\alpha_{2}\left(\omega-c_{p}\right)}{2\left(\omega-c_{p}\right)(\theta-\omega \beta)}
\end{aligned}
$$

in the second period;

Proof. See the Appendix.

It is also clear from Proposition 2 that the return rate impacts the first period decisions only. In comparison to the no return case (Corollary 1), $M$ offers a lower quality in the first period. That is, $\widetilde{A}_{1}^{\mathcal{M}}<\hat{A}_{1}$. Moreover, the (wholesale and retail) prices and the quantities sold will also be lower. Specifically, $\widetilde{p}_{1}^{\mathcal{M}}<\hat{p}_{1}$ and $\widetilde{q}_{1}^{\mathcal{M}}<\hat{q}_{1}$ will hold. Consequently, whether the collection rate is exogenous or price and technology responsive, the returned product causes a reduction in quality and price. The intuition for this result is that firms already know that there will be some returns, and there is indeed a future market for a new product. Quality is costly, and hence $M$ offers a lower quality (hence charges a low price) for the returned product, to sell a higher quality product in the second period at a higher price. We argue that when the game is extended to many periods the quality offered at time $t$ will be higher than the quality offered at time $t-1$ but lower than the quality offered at time $t+1$. 


\section{Scenario $\mathcal{R}$ - The Retailer collection case}

This section examines a specific chain structure in which $R$ collects the end-of-use products from consumers and sends them to $M$ for remanufacturing and recycling. This chain structure involves businesses for which the residual value of return is marginal (e.g., cartridges, cameras) and thus sending it directly to $M$ is logistically feasible but becomes economically inconvenient. Thus, $R$ does the collection and retains a reward $\nu g A_{1}$, where $\nu$ is a per-return incentive that $M$ allocates to $R$. In this game, $M$ is still the channel leader and the game moves over the same stages earlier described in the $\mathcal{M}$-scenario.

Proposition 3. Assuming an interior solution, the equilibrium strategies in the $\mathcal{R}$-scenario are given by:

$$
\begin{aligned}
p_{1}^{\mathcal{R}} & =\frac{\alpha_{1}(1+v)+(\theta(1+v)+\beta \omega) A_{1}^{\mathcal{R}}}{2 \beta(1+v)} \\
q_{1}^{\mathcal{R}} & =\frac{\alpha_{1}(1+v)+(\theta(1+v)-\beta \omega) A_{1}^{\mathcal{R}}}{2(1+v)} \\
A_{1}^{\mathcal{R}} & =\frac{(1+v)^{2}\left\{\beta\left[2 \mu-\alpha_{1}\left(\omega-c_{p}\right)\right]-\alpha_{1} \theta \gamma \delta(\Delta-\phi-(1+\nu) g)\right\}}{2 \beta(1+v)\left(\omega-c_{p}\right)(\theta(1+v)-\omega \beta)+\gamma \delta(\Delta-\phi-(1+\nu) g)(\theta(1+v)-\beta \omega)(\theta(1+v)+\omega \beta)}
\end{aligned}
$$

Proof. See the Appendix.

Note that because the return rate depends on the first-period strategies only, the following holds: $p_{2}^{\mathcal{M}}=$ $p_{2}^{\mathcal{R}}, q_{2}^{\mathcal{M}}=q_{2}^{\mathcal{R}}$, and $A_{2}^{\mathcal{M}}=A_{2}^{\mathcal{R}}$.

We require the following batch of conditions to hold in order to meet the positivity assumptions:

- $\theta(1+v)-\beta \omega>0$

$\checkmark \Delta-\phi-(1+\nu) g>0$, and

- $2 \mu-\alpha_{1}\left(\omega-c_{p}\right)+\alpha_{1} \theta \gamma \delta(\Delta-\phi-(1+\nu) g) / \beta>0$.

First, we require that $\theta(1+v)-\beta \omega>0$ holds, as this is a necessary condition to obtain positive $q_{1}^{\mathcal{R}}$. Also the condition $\Delta-\phi-(1+\nu) g>0$ should hold as the marginal rewards from collection must be larger than the marginal collection cost. Furthermore, $2 \mu>\alpha_{1}\left(\omega-c_{p}\right)+\alpha_{1} \theta \gamma \delta(\Delta-\phi-(1+\nu) g) / \beta$ should hold to have positive quality level $A_{1}^{\mathcal{R}}$, so that $p_{1}^{\mathcal{R}}$ and $q_{1}^{\mathcal{R}}$ also remain positive. Notice that these conditions are similar to those assumed in the $\mathcal{M}$-scenario when the markup $\nu=0$.

The second period decisions are identical no matter who does the collection because the return rate does not depend on the second period strategies. The first period decisions in the $\mathcal{R}$-scenario will differ from the strategies in the $\mathcal{M}$-scenario because of the multiplier $(1+v)$. When $\nu=0$ holds, $v=\delta \gamma g \nu=0$.

Similar to Proposition 1, the higher the $M^{\prime}$ s marginal benefit $(\Delta-\phi-(1+\nu) g)$ is, the lower the quality 
offered in period $1\left(A_{1}^{\mathcal{R}}\right)$. This result implies lower retail price $\left(p_{1}\right)$ and lower sales $\left(q_{1}\right)$. Moreover, the return rate $(r)$ increases in the $M$ 's marginal benefits. Also, the higher the $R$ 's markup $\nu$, the higher will be the $M$ 's quality. That is, $\partial A_{1}^{\mathcal{R}} / \partial \nu>0$. In addition, $\partial p_{1}^{\mathcal{R}} / \partial \nu>0$ and $\partial q_{1}^{\mathcal{R}} / \partial \nu>0$ will hold.

Corollary 3. In the absence of any backward activities, $\gamma=0$, firms' strategies in the $\mathcal{R}$-scenario coincide with those in the $\mathcal{M}$-scenario.

The equilibrium outcomes in Corollary 1 still holds in the absence of backward activities (collection, recycling, remanufacturing), that is $\gamma=0$. In fact, if no customers return their used products, there is no benefit for either of the players. Mathematically, when we plug $v=0$ and $\gamma=0$ into the outcomes in Proposition 3, we obtain the result in Corollary 3. Intuitively, when removing the backward activities, the two scenarios coincide; thus, we strictly require that $\gamma>0$ to pursue the objectives of the paper.

Proposition 4. In the $\mathcal{R}$-scenario, both firms have an incentive to perform the return activities.

Clearly, $\Pi_{M}^{\mathcal{R}}-\Pi_{M \mid \gamma=0}^{\mathcal{R}}>0$ and $\Pi_{R}^{\mathcal{R}}-\Pi_{R \mid \gamma=0}^{\mathcal{R}}>0$ as the marginal profits from backward activities for both players are positive according to the conditions above, while $q_{t}>0$ and $r_{t}>0$ always hold.

Corollary 4. In the $\mathcal{R}$-scenario, consumers who trade-in and save: i) pay a lower price under the collection program; ii) get a better quality in the second period. Specifically, $p_{1}^{\mathcal{R}}<\hat{p}_{1}, p_{2}^{\mathcal{R}}=\hat{p}_{2}$, and $A_{2}^{\mathcal{R}}>$ $A_{1}^{\mathcal{R}}$.

Proof. See the Appendix.

From Proposition 4 and Corollary 4 interesting results emerge: Independently of who does the product collection, closing the loop turns out to be:

- socially beneficial, as the consumers pay lower prices for buying the products;

- environmentally sustainable, as the consumers discard less end-of-use products in the landfill at the end of the product life cycle.

- economically convenient, as both firms gain greater economic rewards.

In sum, closing the loop aligns with firms' business to the triple bottom line, which aims at performing social, environmental and economic performances simultaneously (De Giovanni and Zaccour, 2014), and independently of who does the product collection. Consequently, regulators and legislators should stimulate companies to collect past-sold products by establishing ad-hoc social and/or economic incentives (Kumar and Putnam, 2008).

Proposition 5. In the $R$ scenario, firms gain less under a passive return approach than they do under an active return approach. 
Proof. Because firms impact the return rate through pricing and quality efforts (following the result in Proposition 2), it will always hold that $p_{1}^{\mathcal{R}}>p_{1 \mid r=\gamma}^{\mathcal{R}}, A_{M}^{\mathcal{R}}>A_{M \mid r=\gamma}^{\mathcal{R}}, q_{1}^{\mathcal{R}}>q_{1 \mid r=\gamma}^{\mathcal{R}}, \Pi_{M}^{\mathcal{R}}>\Pi_{M \mid r=\gamma}^{\mathcal{R}}$ and $\Pi_{R}^{\mathcal{R}}>\Pi_{R \mid r=\gamma}^{\mathcal{R}}$.

Notice also that as the second period decisions are the same independently of having the return rate as an endogenous or an exogenous factor, both firms' strategies and and profit functions are not influenced by the return rate.

When $R$ collects, we still obtain the result seen in Proposition 2. That is to say, if we assume an exogenous return rate, we find that $M$ will perform lower quality, prices, and sales in the first period compared to the no return case (Corollary 1). Consequently, customers pay lower prices under any return function, but they also get a lower technology. Notationally, $\widetilde{A}_{1}^{\mathcal{R}}<\hat{A}_{1}, \widetilde{p}_{1}^{\mathcal{R}}<\hat{p}_{1}$, and $\widetilde{q}_{1}^{\mathcal{R}}<\hat{q}_{1}$ would hold.

\section{Numerical comparison and sensitivity analysis}

In the previous sections, we analytically characterized the equilibrium strategies in the $\mathcal{M}$ - and $\mathcal{R}$-scenarios. Not surprisingly, the equilibrium strategies in the second period are equal across the scenarios given the model structure. Accordingly, any difference in the players' strategies and profits between the two scenarios basically depend on the first period decisions. Because strategies and profits are algebraically involved, we will proceed with a numerical analysis. This comparison will provide new managerial insights and contributions to the literature. Indeed, one can always relax certain assumptions, e.g., an exogenous return rate to obtain a less complex model and more analytical results. Given that there are 13 parameters in the model, we have organized a sensitivity analysis in Table 2 to cover all possible cases while representing the findings in a meaningful way. In the main row of Table 2, we present the difference between the firms' strategies and profits. In the main column, we numerically compute the derivatives of each model parameter with respect to one element in the main column. For example, if one crosses the term $\Pi_{M}^{\mathcal{M}}-\Pi_{M}^{\mathcal{R}}>0$ in the main row with $\alpha_{1}$ in the main column, the positive sign should be interpreted as the change in the difference between $M$ 's profits for any change in the market potential. Then, we shall once and for all set the values of some parameters. We fix once for all the following parameters:

$$
\begin{aligned}
& \alpha_{1}=1 ; \beta=0.5 ; \theta=1 ; c_{p}=0.001 ; \gamma=0.2 ; \mu=1 ; \\
& \omega=0.65 ; \Phi_{M}^{\mathcal{M}}=0.5 ; \Phi_{M}^{\mathcal{R}}=0.2 ; \Phi_{R}^{\mathcal{R}}=0.3 ; \delta=0.9 .
\end{aligned}
$$

where: $\Phi_{M}^{\mathcal{M}}=\Delta-\phi-g, \Phi_{M}^{\mathcal{R}}=\Delta-\phi-(1+\nu) g$, and $\Phi_{R}^{\mathcal{R}}=\nu g$. Indeed, we have disregarded the sensitivity analysis for the second-period parameters as they have no influence on the first period strategies. 


\begin{tabular}{|l|l|l|l|l|}
\hline Parameter & $p_{1}^{\mathcal{M}}-p_{1}^{\mathcal{R}}<0$ & $A_{1}^{\mathcal{M}}-A_{1}^{\mathcal{R}}<0$ & $\Pi_{M}^{\mathcal{M}}-\Pi_{M}^{\mathcal{R}}>0$ & $\Pi_{R}^{\mathcal{M}}-\Pi_{R}^{\mathcal{R}}<0$ \\
\hline$\alpha_{1}$ & - & - & + & - \\
\hline$\beta$ & + & + & - & + \\
\hline$\theta$ & - & - & + & - \\
\hline$c_{p}$ & - & - & + & - \\
\hline$\gamma$ & - & - & + & - \\
\hline$\mu$ & - & - & + & - \\
\hline$\omega$ & + & + & - & + \\
\hline$\Phi_{M}^{\mathcal{M}} / \Phi_{M}^{\mathcal{R}}$ & + & + & - & + \\
\hline$\Phi_{R}^{\mathcal{R}}$ & - & - & + & - \\
\hline$\delta$ & - & - & + & - \\
\hline
\end{tabular}

Table 2. Sensitivity analysis

Accordingly, the following claims can be formulated:

Claim 1. Each firm has an economic incentive to perform the return process.

Interestingly, this result is different than what is reported in the CLSC literature in which either a manufacturer (e.g., De Giovanni, 2014) or a retailer (e.g., Savaskan et al., 2004) closes the loop. In our paper, we find that the player who performs the return process has no incentive to move to another type of CLSC structure. Indeed, this result is directly derived from the structure of our model when compared with the ones found in the literature. Our main novelty is the endogenized return rate that depends on both the price and the technology developments rather than on green activities programs or promotional efforts (e.g., Savaskan et al,. 2004; Savaskan and van Wassenhove, 2006, De Giovanni et al., 2015). In conclusion, when a CLSC includes an active price- and technology-based return approach, the collector has no economic incentive to leave its position.

Claim 2. The trade-off between pricing and quality is more pronounced in the $\mathcal{R}$-scenario.

Notice that the $\mathcal{R}$-scenario wins the trade-off between pricing and quality investments. In particular, $M$ invests more in quality efforts and $R$ charges a higher price under an $\mathcal{R}$-scenario. $R$ charges a higher price to enlarge the return rate (see Eq. (??)) and thus increasing her profits by exploiting the backward economic rewards. In contrast, $M$ knows that $R$ will try to increase the return rate as much as possible by setting a proper pricing strategy. A large return rate can hurt $M$ 's profits substantially, so he will try to reduce the return rate by increasing the quality investments in the first period. This result is due to the negative impact of quality on the return rate, which will in turn lead to a larger demand. Finally, higher price and quality imply a more pronounced competition between the firms when $R$ is the collector. 
Claim 3. The larger the double marginalization effect is, the larger the firm's willingness to outsource the return process.

When the double marginalization effect is substantially high due to a large $\omega$, each player has an incentive not to perform the return process. On the one hand, $M$ prefers to outsource the return process to $R$ because this action will lead to a lower pricing, larger demand, and it requires less investments in quality. On the other hand, $R$ wishes $M$ to perform the return process, as this results in a lower quality efforts and, thus, a lower double marginalization. To conclude, the double marginalization effect represents a serious concern in a CLSC as it directly influences the return rate, and hence the CLSC environmental performance.

\section{Competition in the Retail Sector}

This section analyzes the case where there is more than one retailer in the downstream market in which the final good is sold. Essentially, we add competition to the retail sector in the CLSC model introduced in Section 2. We expect competition to reduce both the retail and the wholesale prices. We uncover the extent to which the downstream competition impacts the M's decision making process. We solve the CLSC model backwards to characterize the subgame perfect equilibrium. Assume that there are $n$ retailers, and denote $i$ for a retailer, $i=1,2,3, \ldots, n$. Retailers simultaneously and independently choose their strategies.

\subsection{Collection is carried out by the manufacturer under retail competition}

Similar to Section 3, where $M$ has handled the collection process facing only a single retailer, we now extend this analysis to include $n$ retailers. In this model, we assume that while $M$ collects all past-sold products and retains all economic advantages from closing the loop, $n$ identical retailers are present in the market and compete in the forward flow business. Therefore, we assume that none of the $n$ retailers interferes with the product collection. Accordingly, we characterize the game in four stages of two periods and obtain the following result.

Proposition 6: Assume that $M$ collects the used products and $n$ retailers compete in the downstream market. Then, the unique Stackelberg subgame perfect equilibrium market outcomes are the following:

In period 2,

each retailer sells $q_{i 2}^{C M}=\frac{(n+1) \mu+n \alpha_{2}\left(\omega-c_{p}\right)}{2 n(n+1)\left(\omega-c_{p}\right)}, i=1,2,3, \ldots, n$,

the quality is $A_{2}^{C M}=\frac{(n+1) \mu-n \alpha_{2}\left(\omega-c_{p}\right)}{2 n\left(\omega-c_{p}\right)(\theta-\omega \beta)}$,

the total sales is $q_{2}^{C M}=\frac{(n+1) \mu+n \alpha_{2}\left(\omega-c_{p}\right)}{2(n+1)\left(\omega-c_{p}\right)}$, 
and the market price is $p_{2}^{C M}=\frac{(n+1) \mu(\theta+n \omega \beta)+n \alpha_{2}\left(\omega-c_{p}\right)(\theta-(2+n) \omega \beta)}{2 n(n+1) \beta\left(\omega-c_{p}\right)(\theta-\omega \beta)}$.

In period 1,

the total sales is $q_{1}^{C M}=\frac{n \alpha_{1}+n A_{1}(\theta-\beta \omega)}{(n+1)}$,

the market price is $p_{1}^{C M}=\frac{\alpha_{1}+A_{1}(\theta+n \beta \omega)}{(n+1) \beta}$, where

the quality is $A_{1}^{C M}=\frac{(n+1)^{2} \beta \mu-n \alpha_{1}\left[\beta(n+1)\left(\omega-c_{p}\right)+\gamma \delta(\Delta-\phi-g)(2 \theta-\beta \omega(1+n))\right]}{2 n(\theta-\omega \beta)\left[\beta\left(\omega-c_{p}\right)(n+1)+\gamma \delta(\Delta-\phi-g)(\theta+n \omega \beta)\right]}$.

See the Appendix.

We use the superscript "CM" to refer to the competitive retail sector $(\mathrm{C})$ and collection handled by the manufacturer (M). First, observe that when we plug $n=1$ into the above proposition outcomes, we obtain the same results as we did in Proposition 1 with a single retailer. Each retailer will sell the same amount because all retailers are symmetric in costs (facing the same manufacturer without any price discrimination) and serve the same consumers.

As the following proposition shows, the consumers are better off under competition. Namely, they pay lower prices and consume more, but at the expense of lower quality. This result contrasts with all the previous research in supply chain management on quality and pricing (e.g., El Ouardighi and Kim, 2012). In particular, when competition is present, competition on quality is more pronounced than competition on pricing. This finding is not at all confirmed in a CLSC framework, as we find exactly the opposite. Our results have roots in the economic and marketing theory according to which price remains the main lever that consumers evaluate, independently of some other factors (e.g., technological progress).

Proposition 7: When $M$ collects the used products, it offers lower quality products to the competitive $n$-retailer market, charges lower prices, and sells more products, in comparison to the monopolistic retail market. Each retailer charges a lower price to the customers under competition.

Proof: We directly compare the outcomes in Propositions 1 and 6 . The quality offered in the second period under retail competition is $A_{2}^{C M}=\frac{(n+1) \mu-n \alpha_{2}\left(\omega-c_{p}\right)}{2 n\left(\omega-c_{p}\right)(\theta-\omega \beta)}$, while it is $A_{2}^{\mathcal{M}}=\frac{2 \mu-\alpha_{2}\left(\omega-c_{p}\right)}{2\left(\omega-c_{p}\right)(\theta-\omega \beta)}$ without retail competition. The difference is $A_{2}^{\mathcal{M}}-A_{2}^{C M}=\frac{(n-1) \mu}{2 n\left(\omega-c_{p}\right)(\theta-\omega \beta)}>0$ because $n$ is greater than one. Therefore, the difference between wholesale prices is $\omega\left(A_{2}^{\mathcal{M}}-A_{2}^{C M}\right)>0$. For the retailer, the difference between the price levels is $p_{2}^{\mathcal{M}}-p_{2}^{C M}=\left[2\left(n^{2}-1\right) \mu \theta+n(n-1) \alpha_{2}\left(\omega-c_{p}\right)(\theta-\omega \beta)\right] /$ constant $1>0$ because the terms in brackets are positive, and the constant 1 is a positive constant which is the common factor of the denominator. However, the total sales are higher under the competition. That is, $q_{2}^{C M}-q_{2}^{\mathcal{M}}=\alpha_{2}(n-1) / 4(n+1)>0$. Similar results are obtained for the first period 
Corollary 5: When $M$ collects and the retailers compete (i.e., $n \rightarrow \infty$ ), the following outcomes hold:

1. The second period decisions are:

$\lim _{n \rightarrow \infty} p_{2}^{C M}=\frac{\omega\left(\mu-\alpha_{2}\left(\omega-c_{p}\right)\right)}{2\left(\omega-c_{p}\right)(\theta-\omega \beta)}$ for the price,

$\lim _{n \rightarrow \infty} q_{2}^{C M}=\frac{\mu+\alpha_{2}\left(\omega-c_{p}\right)}{2\left(\omega-c_{p}\right)}$ for the sales, and

$\lim _{n \rightarrow \infty} A_{2}^{C M}=\frac{\mu-\alpha_{2}\left(\omega-c_{p}\right)}{2\left(\omega-c_{p}\right)(\theta-\omega \beta)}$ for the quality.

2. The first period decisions are

$$
\begin{aligned}
& \lim _{n \rightarrow \infty} p_{1}^{C M}=\frac{\omega \mu+\omega \alpha_{1}\left[\delta \gamma \omega(\Delta-\phi-g)-\left(\omega-c_{p}\right)\right]}{2(\theta-\omega \beta)\left[\delta \gamma \omega(\Delta-\phi-g)+\left(\omega-c_{p}\right)\right]}, \\
& \lim _{n \rightarrow \infty} q_{1}^{C M}=\frac{\mu+\alpha_{1}\left[\delta \gamma \omega(\Delta-\phi-g)-\left(\omega-c_{p}\right)\right]}{2\left[\delta \gamma \omega(\Delta-\phi-g)+\left(\omega-c_{p}\right)\right]}, \\
& \lim _{n \rightarrow \infty} A_{1}^{C M}=\frac{\mu+\alpha_{1}\left[\delta \gamma \omega(\Delta-\phi-g)-\left(\omega-c_{p}\right)\right]}{2(\theta-\omega \beta)\left[\delta \gamma \omega(\Delta-\phi-g)+\left(\omega-c_{p}\right)\right]} .
\end{aligned}
$$

The proof of Corollary 5 is immediately obtained by applying the basic limit laws and the L'Hopital's rule several times.

Note that Corollary 5 does not show welfare (consumer and producer surplus) maximizing or social optimum outcomes, because the upstream is still controlled by a single manufacturer. With the single manufacturer and the single retailer case (Proposition 1) we obtain the worst outcomes possible for the consumers due to double marginalization in the forward channel. $M$ also suffers from having a single retailer in the downstream. If possible, he prefers the vertical integration. If this is not possible, say due to an organizational structure or regulatory restrictions, he prefers having a competitive retailer market, in which the equilibrium outcomes are outlined as stated in Proposition 6 and Corollary 5. Clearly, both $M$ and the consumers are better off under retail competition. As it can be seen from Corollary 5 , the retailers charge the marginal cost of production to the consumers and end up with zero economic profit. $M$ completely avoids the harm of double marginalization by having a perfectly competitive retail market and enjoys the highest possible profit. Of course, the consumers would also prefer seeing a competitive upstream market. However, the equilibrium outcomes in Corollary 5 are the best results (the lowest prices and the highest consumption levels) obtained in this model.

\subsection{Collection is carried out by the retailers under retail competition}

We now characterize a model in which there are $n$ identical retailers competing not only in terms of forward flows but also in terms of returns. Since the retailers are symmetric in costs (facing the same manufacturer 
who does not price discriminate) and facing the same customers type, it makes sense to assume that each retailer collects the same amount of returned products. That is, each one collects $r(.) q_{1}() /$.$n units of product.$ Noting that payment made by the manufacturer to each retailer is $\nu g A_{1}$, then the collection is worthwhile if $\Delta A_{1}-(1+\nu) g A_{1}-\phi A_{1} \geq 0$.

Proposition 8: Assume that there are $n$ retailers who compete in the downstream market and handle the collection process. Then the unique Stackelberg equilibrium market outcomes in the supply chain are the following:

In period 2

each retailer sells $q_{i 2}^{C R}=\frac{(n+1) \mu+n \alpha_{2}\left(\omega-c_{p}\right)}{2 n(n+1)\left(\omega-c_{p}\right)}, i=1,2,3, \ldots, n$.,

the quality is $A_{2}^{C R}=\frac{(n+1) \mu-n \alpha_{2}\left(\omega-c_{p}\right)}{2 n\left(\omega-c_{p}\right)(\theta-\omega \beta)}$,

the market price is $p_{2}^{C R}=\frac{(n+1) \mu(\theta+n \omega \beta)+n \alpha_{2}\left(\omega-c_{p}\right)(\theta-(2+n) \omega \beta)}{2 n(n+1) \beta\left(\omega-c_{p}\right)(\theta-\omega \beta)}$.

In period 1,

each retailer sells $q_{i 1}^{C R}=\frac{\alpha_{1}(n+v)+(\theta(n+v)-n \beta \omega) A_{1}}{n(n+1+2 v)}$ and

the market price is $p_{1}^{C R}=\frac{\alpha_{1}(1+v)+A_{1}(\theta(1+v)+n \beta \omega)}{(n+1+2 v) \beta}$, where

the quality is

$A_{1}^{C R}=\frac{(n+1+2 v) \beta\left[\mu(n+1+2 v)-\alpha_{1}(n+v)\left(\omega-c_{p}\right)\right]-\alpha_{1} \tilde{\Delta}[2 \theta(1+v)(n+v)+n(n-1) \beta \omega]}{2 \tilde{\Delta}(\theta(1+v)+n \omega \beta)(\theta(n+v)-n \omega \beta)+2 \beta\left(\omega-c_{p}\right)(n+1+2 v)(\theta(n+v)-n \omega \beta)}$,

where $\tilde{\Delta}=\delta \gamma(\Delta-\phi-(1+\nu) g)$, and $v=\delta \gamma g \nu$.

See the Appendix.

Above, we use superscript "CR" to refer to the competitive retail sector $(\mathrm{C})$ in which collection is handled by the retailers $(\mathrm{R})$. Observe that when we plug $n=1$ into the above proposition, we obtain exactly the equilibrium results as in Proposition 3, with a single retailer case. Each retailer sells the same amount because the retailers are symmetric in their costs and serve the same consumer type.

The following proposition is in the vein of Proposition 7, where $M$ handles the collection.

Proposition 9: When the retailers collect, each retailer charges lower prices to the customers under competition. $M$ offers a lower quality to the $n$ competitive retailers, charges lower prices, and sells more products, comparatively to the monopolistic retail market.

Proof: We directly compare the outcomes in Propositions 3 and 8 . The quality offered in the second period is $A_{2}^{C R}=\frac{(n+1) \mu-n \alpha_{2}\left(\omega-c_{p}\right)}{2 n\left(\omega-c_{p}\right)(\theta-\omega \beta)}$ under retail competition, while it is $A_{2}^{\mathcal{R}}=\frac{2 \mu-\alpha_{2}\left(\omega-c_{p}\right)}{2\left(\omega-c_{p}\right)(\theta-\omega \beta)}$ without 
retail competition. The difference is $A_{2}^{\mathcal{R}}-A_{2}^{C R}=\frac{(n-1) \mu}{2 n\left(\omega-c_{p}\right)(\theta-\omega \beta)}>0$ because $n$ is larger than one. Therefore, the manufacturer's wholesale prices compare $\omega\left(A_{2}^{\mathcal{R}}-A_{2}^{C R}\right)>0$. For a retailer, the difference between the price levels is $p_{2}^{\mathcal{R}}-p_{2}^{C R}=\left[2\left(n^{2}-1\right) \mu \theta+n(n-1) \alpha_{2}\left(\omega-c_{p}\right)(\theta-\omega \beta)\right] /$ constant $2>0$ because the terms in brackets are positive, and the constant 2 is a positive constant representing the common factor of the denominator. However, the total sales are higher under the competition. That is, $q_{2}^{C R}-q_{2}^{\mathcal{R}}=(n-1) \alpha_{2} / 4(n-1)>0$. Similar results are obtained in the first period .

Corollary 6: When $n$ competitive retailers collect, the following outcomes hold:

1. The second period decisions are:

$\lim _{n \rightarrow \infty} p_{2}^{C R}=\frac{\omega\left(\mu-\alpha_{2}\left(\omega-c_{p}\right)\right)}{2\left(\omega-c_{p}\right)(\theta-\omega \beta)}$ for the price,

$\lim _{n \rightarrow \infty} q_{2}^{C R}=\frac{\mu+\alpha_{2}\left(\omega-c_{p}\right)}{2\left(\omega-c_{p}\right)}$ for the sales, and

$\lim _{n \rightarrow \infty} A_{2}^{C R}=\frac{\mu-\alpha_{2}\left(\omega-c_{p}\right)}{2\left(\omega-c_{p}\right)(\theta-\omega \beta)}$ for the quality.

2. The first period decisions are:

$$
\begin{aligned}
& \lim _{n \rightarrow \infty} p_{1}^{C R}=\frac{\mu \omega-\alpha_{1} \omega\left[\delta \gamma \omega(\Delta-\phi-g(1+\nu))+\left(\omega-c_{p}\right)\right]}{2(\theta-\omega \beta)\left[\delta \gamma \omega(\Delta-\phi-g(1+\nu))+\left(\omega-c_{p}\right)\right]}, \\
& \lim _{n \rightarrow \infty} q_{1}^{C R}=\frac{\mu-\alpha_{1}\left[\delta \gamma \omega(\Delta-\phi-g(1+\nu))+\left(\omega-c_{p}\right)\right]}{2\left[\delta \gamma \omega(\Delta-\phi-g(1+\nu))+\left(\omega-c_{p}\right)\right]}, \\
& \lim _{n \rightarrow \infty} A_{1}^{C R}=\frac{\mu-\alpha_{1}\left[\delta \gamma \omega(\Delta-\phi-g(1+\nu))+\left(\omega-c_{p}\right)\right]}{2(\theta-\omega \beta)\left[\delta \gamma \omega(\Delta-\phi-g(1+\nu))+\left(\omega-c_{p}\right)\right]} .
\end{aligned}
$$

The proof of Corollary 6 is immediately obtained by applying the limit laws of addition and multiplication together with the L'Hopital's rule.

Similar to Corollary 5, Corollary 6 does not show the welfare maximizing outcome, because the upstream is still controlled by a single manufacturer. Although $M$ loses some profits by not collecting the used products, this is not a significant issue. In fact, $M$ not only enjoys being the supply chain leader but also benefits from competition in the retail sector by eliminating the double marginalization problem.

\subsection{The Impact of Collection Program under Perfect Competition}

An analytical comparison of the market outcomes under different collectors seems to be a daunting task due to many parameters and the involved expressions for quality, price and sales in Propositions 6 and 8 . However, we can perform this analysis analytically in a perfectly competitive retail sector. The following proposition ranks these market outcomes. 
Proposition 10: Assume perfect competition in the retail market. It then matters who handles the collection process for the market participants. Specifically, consumers pay (weakly) lower prices if retailers collect the used products. However, they consume (weakly) lower quantities at (weakly) lower qualities under the retailers' collection program.

Proof: It suffices to compare the market outcomes in Corollaries 5 and 6 . First of all, observe that the market outcomes (price, sales, and quality) in period 2 are identical in both Corollaries. We rewrite the second period quality expressions:

$\lim _{n \rightarrow \infty} A_{1}^{C M}=\frac{\mu}{2(\theta-\omega \beta)\left[\delta \gamma \omega(\Delta-\phi-g)+\left(\omega-c_{p}\right)\right]}+\frac{\alpha_{1}\left[\delta \gamma \omega(\Delta-\phi-g)-\left(\omega-c_{p}\right)\right]}{2(\theta-\omega \beta)\left[\delta \gamma \omega(\Delta-\phi-g)+\left(\omega-c_{p}\right)\right]}$,

when the manufacturer collects under retail competition $(\mathrm{CM})$.

$\lim _{n \rightarrow \infty} A_{1}^{C R}=\frac{\mu}{2(\theta-\omega \beta)\left[\delta \gamma \omega(\Delta-\phi-g(1+\nu))+\left(\omega-c_{p}\right)\right]}-\frac{\alpha_{1}\left[\delta \gamma \omega(\Delta-\phi-g(1+\nu))+\left(\omega-c_{p}\right)\right]}{2(\theta-\omega \beta)\left[\delta \gamma \omega(\Delta-\phi-g(1+\nu))+\left(\omega-c_{p}\right)\right]}$, when the retailers collect under retail competition (CR).

Observe that the first quotient in $\lim _{n \rightarrow \infty} A_{1}^{C M}$ is higher than the one in $\lim _{n \rightarrow \infty} A_{1}^{C R}$.

Also, the second quotient in $\lim _{n \rightarrow \infty} A_{1}^{C M}$ is positive and the second one in $\lim _{n \rightarrow \infty} A_{1}^{C R}$ is negative. Therefore, $\lim _{n \rightarrow \infty} A_{1}^{C M}>\lim _{n \rightarrow \infty} A_{1}^{C R}$. Using the same arguments, $\lim _{n \rightarrow \infty} p_{1}^{C M}>\lim _{n \rightarrow \infty} p_{1}^{C R}$ and $\lim _{n \rightarrow \infty} q_{1}^{C M}>\lim _{n \rightarrow \infty} q_{1}^{C R}$ hold.

\section{Conclusions}

The main contribution of this paper is the consideration of price- and technology-dependent demand and return in a CLSC model. This structure is highly relevant nowadays because consumer utility is a function of price and technology, among other factors. Another feature we add into the model is retail competition. Indeed, in any actual market no profit maximizing manufacturer chooses to sell its product through a single retailer. As it is well known, having an $n$ retailers in the downstream market allows the manufacturer to avoid the double marginalization.

We obtained the following results independently of whoever (manufacturer or retailer) does the collection. We find that wholesale and retail prices increase in quality, but the collection (or used product return) rate decreases in quality. Interestingly, when the (marginal) value of the collection is higher to the manufacturer, it prefers to offer lower quality in the first period. However, he always chooses better quality product in the second period. As the quality is lower in the first period, prices are also lower at all supply chain levels. Moreover, if the manufacturer spends more to supply high technology products, he then charges a higher wholesale price. This in turn implies a higher retail price and larger sales.

Further, the manufacturer offers higher quality when the collection process is absent to overcome the loss of rewards from returns. Also, the existence of a collection program signals the technology level. Finally, each 
supply chain member seeks to be the CLSC collector and has neither operational nor economic incentives to leave this position.

When we introduce competition into the retail market, we find that both consumers and the manufacturer are better off. Namely, the manufacturer increases its profit, and consumers pay lower prices and consume more, but at the expense of a lower quality. In the limiting case, which is a perfectly competitive retail sector, the manufacturer becomes a sole monopoly by eliminating market power in the downstream industry. Hence, the best payoffs are obtained for both the manufacturer and the consumers under retail competition.

There are several ways to extend the current research. First, because of the model setting, the second period strategies do not impact the return rate, although we were able to quantify the differences between the strategies over time. Letting the return rate be a function of both the first and the second period decisions would in fact change deeply our results. Second, we assume that legislation does not play a formal role in the model. Introducing one more player (e.g., the government) that decides certain legislation constraints would broaden the research scope. However, the current setting of the model would allow government to tax the returned products. This tax could be applied to the payment the customer gets per return. In this case, the results reported in this paper will remain intact because each customer is paid a fix fee per return and the return rate is just a function of market price and product quality. Nevertheless, the model could be expanded to allow the return rate to be affected by taxes applied to different layers of the product chain. Third, we assume there is no channel coordination or integration between the firms. Several types of coordination mechanisms and integration strategies could be further explored to measure their impact on market outcomes (Glock and Kim, 2015). Fourth, of course, consumers would like to see some competition in the upstream market, so they could benefit from further price reductions. This aspect can be an interesting future research direction, because consumers would ultimately demand "variety" in the upstream.

\section{Appendix}

\section{Proof of Proposition 1:}

The profit function is strictly concave in price and quality and hence admits a unique solution. The first order conditions will be sufficient for obtaining maximum values.

This problem is solved backwards because current decisions impact future strategies and profits.

Stage 4: $R$ chooses the price $p_{2}$ that optimizes its second period profit, i.e.,

$\max _{p_{2}} \pi_{R_{2}}=q_{2}\left(A_{2}, p_{2}\right)\left(p_{2}-\omega A_{2}\right)$

Assuming an interior solution, $R$ 's reaction function is 
$p_{2}\left(A_{2}\right)=\frac{\alpha_{2}+\theta A_{2}+\beta \omega A_{2}}{2 \beta}$.

Clearly the retail price increases in market size and product quality. Also, observe that the retail price is an increasing function of the wholesale price $\omega A_{2}$.

Stage 3: The wholesaler $M$ optimizes its second period profit to choose the level of technology/quality $A_{2}$, taking $R$ 's reaction function into account. That is,

$$
\max _{A_{2}} \pi_{M_{2}}=q_{2}\left(A_{2}, p_{2}\right)\left(\omega A_{2}-c_{p} A_{2}\right)-\mu A_{2}+r(.) q_{1}(.)(\Delta-g-\phi) A_{1} .
$$

The first order condition yields

$$
A_{2}=\frac{2 \mu-\alpha_{2}\left(\omega-c_{p}\right)}{2\left(\omega-c_{p}\right)(\theta-\omega \beta)} \text {. }
$$

As expected, the higher the marginal cost of producing quality $(\mu)$ is, the higher the level of quality $A_{2}$

is. Plugging this $A_{2}$ into $q_{2}$ and $p_{2}$ we obtain

$q_{2}=\frac{2 \mu+\alpha_{2}\left(\omega-c_{p}\right)}{4\left(\omega-c_{p}\right)}$, and $p_{2}=\frac{2 \mu(\theta+\omega \beta)+\alpha_{2}\left(\omega-c_{p}\right)(\theta-3 \omega \beta)}{4 \beta(\theta-\omega \beta)\left(\omega-c_{p}\right)}$.

Note that some consumers return the used products in the second period at the rate $r\left(A_{1}, p_{1}\right)=\gamma p_{1} / A_{1}$ to $M$

Stage 2: Moving to the first period, the retailer optimally chooses its price $p_{1}$ to maximize its sum of discounted profits. Namely,

$$
\max _{p_{1}} \pi_{R_{1}}+\delta \pi_{R_{2}}=q_{1}\left(A_{1}, p_{1}\right)\left(p_{1}-\omega A_{1}\right)+\delta q_{2}\left(A_{2}, p_{2}\right)\left(p_{2}-\omega A_{2}\right) .
$$

Substituting the values of $A_{2}$ and $p_{2}$ into the above expression and taking the derivative with respect to $p_{1}$ yields

$p_{1}\left(A_{1}\right)=\frac{\alpha_{1}+\theta A_{1}+\beta \omega A_{1}}{2 \beta}$. Then from demand function the output becomes $q_{1}\left(A_{1}\right)=\frac{\alpha_{1}+\theta A_{1}-\beta \omega A_{1}}{2}$, where the quality decision $A_{1}$ is determined in the first stage.

Stage 1: Since the first period decision impacts its first and second period profits, $M$ chooses $A_{1}$ by solving its aggregate profits in the two periods. That is,

$$
\max _{A_{1}} \pi_{M_{1}}+\delta \pi_{M_{2}}=q_{1}\left(A_{1}, p_{1}\right)\left(\omega A_{1}-c_{p} A_{1}\right)-\mu A_{1}+\delta\left[q_{2}\left(A_{2}, p_{2}\right)\left(\omega A_{2}-c_{p} A_{2}\right)-\mu A_{2}+r\left(A_{1}, p_{1}\left(A_{1}\right)\right) q_{1}\left(A_{1}, p_{1}\left(A_{1}\right)\right)\left(\Delta A_{1}-\right.\right.
$$
$\left.\left.(\phi+g) A_{1}\right)\right]$.

Substituting $p_{1}\left(A_{1}\right), r\left(A_{1}\right)$, and $q_{1}\left(A_{1}\right)$ into the above maximization problem, the total profit expression becomes

$$
\begin{aligned}
& \pi_{M_{1}}+\delta \pi_{M_{2}}=\left(\alpha_{1}+\theta A_{1}-\omega \beta A_{1}\right)\left(\omega A_{1}-c_{p} A_{1}\right) / 2-\mu A_{1}+\delta\left[\left(\alpha_{2}+\theta A_{2}-\omega \beta A_{2}\right)\left(\omega A_{2}-c_{p} A_{2}\right) / 2-\mu A_{2}+\right. \\
& \left.\gamma\left(\alpha_{1}+\theta A_{1}+\omega \beta A_{1}\right)(\Delta-\phi-g)\left(\alpha_{1}+\theta A_{1}-\omega \beta A_{1}\right) / 4 \beta\right]
\end{aligned}
$$

The first order condition for the profit maximization with respect to $A_{1}$ is $\alpha_{1}\left(\omega-c_{p}\right) / 2+A_{1}\left(\theta\left(\omega-c_{p}\right)-\omega \beta\left(\omega-c_{p}\right)\right)-\mu+\delta \gamma(\Delta-\phi-g)\left[A_{1}(\theta-\omega \beta)(\theta+\omega \beta)+\alpha_{1} \theta\right] / 2 \beta=0$.

This yields the optimizing value for $A_{1}$, which is

$$
A_{1}=\frac{\beta\left[2 \mu-\alpha_{1}\left(\omega-c_{p}\right)\right]-\alpha_{1} \theta \gamma \delta(\Delta-\phi-g)}{2 \beta\left(\omega-c_{p}\right)(\theta-\omega \beta)+\gamma \delta(\Delta-\phi-g)(\theta-\beta \omega)(\theta+\omega \beta)} .
$$


Plugging the above $A_{1}$ back into $p_{1}\left(A_{1}\right), q_{1}($.$) , and r($.$) we obtain equilibrium price and quantity in period$ 1 , and return rate as functions of all model parameters.

\section{Proof of Corollary 1:}

When we plug $\gamma=0$ into the equilibrium strategies in Proposition 1, we obtain the result in the corollary.

\section{Proof of Corollary 2:}

This result follows from Proposition 1 where we have shown that consumers pay weakly lower prices under collection process, that is $p_{1}^{M}<\hat{p}_{1}$ and $p_{2}^{M}=\hat{p}_{2}$. Futhermore, $A_{2}^{M}>\hat{A}_{1}^{M}$.

\section{Proof of Proposition 2:}

The difference between Proposition 1 and 3 is how Stage 1 is formulated. The derivations in all the other stages are identical.

Stage 1: Since the first period decision impacts its first and second period profits, $M$ chooses $A_{1}$ by solving its aggregate profits in the two periods. That is,

$$
\max _{A_{1}} \pi_{M_{1}}+\delta \pi_{M_{2}}=q_{1}\left(A_{1}, p_{1}\right)\left(\omega A_{1}-c_{p} A_{1}\right)-\mu A_{1}+\delta\left[q_{2}\left(A_{2}, p_{2}\right)\left(\omega A_{2}-c_{p} A_{2}\right)-\mu A_{2}+r q_{1}\left(A_{1}, p_{1}\left(A_{1}\right)\right)\left(\Delta A_{1}-\right.\right.
$$
$\left.\left.(\phi+g) A_{1}\right)\right]$.

Substituting $p_{1}\left(A_{1}\right), r$, and $q_{1}\left(A_{1}\right)$ into the above maximization problem, the total profit expression becomes

$$
\begin{aligned}
& \pi_{M_{1}}+\delta \pi_{M_{2}}=\left(\alpha_{1}+\theta A_{1}-\omega \beta A_{1}\right)\left(\omega A_{1}-c_{p} A_{1}\right) / 2-\mu A_{1}+\delta\left[\left(\alpha_{2}+\theta A_{2}-\omega \beta A_{2}\right)\left(\omega A_{2}-c_{p} A_{2}\right) / 2-\mu A_{2}+\right. \\
& \left.\gamma A_{1}(\Delta-\phi-g)\left(\alpha_{1}+\theta A_{1}-\omega \beta A_{1}\right) / 2\right]
\end{aligned}
$$

The first order condition for the profit maximization with respect to $A_{1}$ is

$\alpha_{1}\left(\omega-c_{p}\right) / 2+A_{1}\left(\theta\left(\omega-c_{p}\right)-\omega \beta\left(\omega-c_{p}\right)\right)-\mu+\delta \gamma(\Delta-\phi-g)\left[2 A_{1}(\theta-\omega \beta)+\alpha_{1}\right] / 2=0$.

This yields the optimizing value for $A_{1}$, which is

$$
\widetilde{A}_{1}^{M}=\frac{2 \mu-\alpha_{1}\left[\omega-c_{p}+\gamma \delta(\Delta-\phi-g)\right]}{2(\theta-\omega \beta)\left[\omega-c_{p}+\gamma \delta(\Delta-\phi-g)\right]} .
$$

Plugging the above $\widetilde{A}_{1}^{M}$ back into $p_{1}\left(A_{1}\right)$ and $q_{1}($.$) , we obtain equilibrium price and quantity of consump-$ tion in period 1 as function of all the model parameters.

\section{Proof of Proposition 3:}

The structure of the proof is similar to the one in Proposition 1. This problem is solved backwards as the collection decision in the second period will impact the first period decisions. The second period decisions 
will be intact because there is no future and the collection rate only impacts the first period decisions of both $R$ and $M$.

Stage 4: $R$ chooses the price $p_{2}$ that optimizes its second period profits, i.e., $\max _{p_{2}} \pi_{R_{2}}=q_{2}\left(A_{2}, p_{2}\right)\left(p_{2}-\omega A_{2}\right)+r(.) q_{1}(.) \nu g A_{1}$.

Assuming an interior solution, $R$ 's reaction function is

$p_{2}\left(A_{2}\right)=\frac{\alpha_{2}+\theta A_{2}+\beta \omega A_{2}}{2 \beta}$.

Stage 3: $M$ optimizes its second period profits to choose the level of quality $A_{2}$, taking the $R$ 's reaction function into account. That is,

$\max _{A_{2}} \pi_{M_{2}}=q_{2}\left(A_{2}, p_{2}\right)\left(\omega A_{2}-c_{p} A_{2}\right)-\mu A_{2}+r(.) q_{1}().(\Delta-g(1+\nu)-\phi) A_{1}$.

The first order condition yields

$A_{2}^{R}=\frac{2 \mu-\alpha_{2}\left(\omega-c_{p}\right)}{2\left(\omega-c_{p}\right)(\theta-\omega \beta)}$.

Plugging this $A_{2}$ into $q_{2}$ and $p_{2}$ we obtain

$q_{2}^{R}=\frac{2 \mu+\alpha_{2}\left(\omega-c_{p}\right)}{4\left(\omega-c_{p}\right)}$, and $p_{2}^{R}=\frac{2 \mu(\theta+\omega \beta)+\alpha_{2}\left(\omega-c_{p}\right)(\theta-3 \omega \beta)}{4 \beta(\theta-\omega \beta)\left(\omega-c_{p}\right)}$.

Note that some of the consumers choose to return the used products in the second period at the rate $r\left(A_{1}, p_{1}\right)=\gamma p_{1} / A_{1}$ to $R$.

Stage 2: Moving to the first period, $R$ optimally chooses its price $p_{1}$ to maximize its sum of discounted profits. Namely,

$$
\max _{p_{1}} \pi_{R_{1}}+\delta \pi_{R_{2}}=q_{1}\left(A_{1}, p_{1}\right)\left(p_{1}-\omega A_{1}\right)+\delta\left[q_{2}\left(A_{2}, p_{2}\right)\left(p_{2}-\omega A_{2}\right)+\gamma p_{1} q_{1}\left(A_{1}, p_{1}\right) \nu g\right] .
$$

Substituting the values of $A_{2}$ and $p_{2}$ into the above expression and taking the derivative with respect to $p_{1}$ yields

$p_{1}\left(A_{1}\right)=\frac{\alpha_{1}(1+v)+(\theta(1+v)+\beta \omega) A_{1}}{2 \beta(1+v)}$, where $v=\delta \gamma g \nu$. Plugging this price into the demand function results in $q_{1}\left(A_{1}\right)=\frac{\alpha_{1}(1+v)+(\theta(1+v)-\beta \omega) A_{1}}{2(1+v)}$, where the quality decision $A_{1}$ is determined in the first stage.

Stage 1: Since the first period decision impacts its first and second period profits, $M$ chooses $A_{1}$ by solving its aggregate profits in two periods. That is,

$$
\begin{aligned}
& \quad \max _{A_{1}} \pi_{M_{1}}+\delta \pi_{M_{2}}=q_{1}\left(A_{1}, p_{1}\right)\left(\omega A_{1}-c_{p} A_{1}\right)-\mu A_{1}+\delta\left[q_{2}\left(A_{2}, p_{2}\right)\left(\omega A_{2}-c_{p} A_{2}\right)-\mu A_{2}+r\left(A_{1}, p_{1}\left(A_{1}\right)\right) q_{1}\left(A_{1}, p_{1}\left(A_{1}\right)\right)\left(\Delta A_{1}-\right.\right. \\
& \left.\left.(\phi+(1+\nu) g) A_{1}\right)\right] .
\end{aligned}
$$

Substituting $p_{1}\left(A_{1}\right), r\left(A_{1}\right)$, and $q_{1}\left(A_{1}\right)$ into the above maximization problem, the profit expressions become

$$
\begin{aligned}
& \quad \pi_{M_{1}}=\left[\alpha_{1}(1+v)+A_{1}(\theta(1+v)-\omega \beta)\right]\left(\omega A_{1}-c_{p} A_{1}\right) / 2(1+v)-\mu A_{1} \\
& \pi_{M_{2}}=\left[\left(\alpha_{2}+\theta A_{2}-\omega \beta A_{2}\right)\left(\omega A_{2}-c_{p} A_{2}\right) / 2-\mu A_{2}+\gamma\left[\alpha_{1}(1+v)+(\theta(1+v)+\beta \omega) A_{1}\right]\left[\alpha_{1}(1+v)+(\theta(1+\right.\right. \\
& \left.\left.v)-\beta \omega) A_{1}\right](\Delta-\phi-(1+\nu) g) / 4 \beta(1+v)^{2}\right]
\end{aligned}
$$


The first order condition for the sum of the discounted profit maximization with respect to $A_{1}$ leads to $A_{1}^{R}=\frac{(1+v)^{2}\left\{\beta\left[2 \mu-\alpha_{1}\left(\omega-c_{p}\right)\right]-\alpha_{1} \theta \gamma \delta(\Delta-\phi-(1+\nu) g)\right\}}{2 \beta(1+v)\left(\omega-c_{p}\right)(\theta(1+v)-\omega \beta)+\gamma \delta(\Delta-\phi-(1+\nu) g)(\theta(1+v)-\beta \omega)(\theta(1+v)+\omega \beta)}$.

Plugging this quality level back into $p_{1}\left(A_{1}\right), q_{1}\left(A_{1}\right)$, and $r($.$) we obtain Stackelberg equilibrium price$ and quantity in period 1, and return rate as functions of all model parameters.

\section{Proof of Corollary 4:}

It suffices to compare the quality levels in the first period.

When $R$ collects used products, the quality offered in the first period, as proved in Proposition 3 , is $A_{1}^{R}=\frac{(1+v)^{2}\left\{\beta\left[2 \mu-\alpha_{1}\left(\omega-c_{p}\right)\right]-\alpha_{1} \theta \gamma \delta(\Delta-\phi-(1+\nu) g)\right\}}{2 \beta(1+v)\left(\omega-c_{p}\right)(\theta(1+v)-\omega \beta)+\gamma \delta(\Delta-\phi-(1+\nu) g)(\theta(1+v)-\beta \omega)(\theta(1+v)+\omega \beta)}$.

When collection program was not offered, as shown in Corollary 1 ,

$\hat{A}_{1}=\frac{2 \mu-\alpha_{1}\left(\omega-c_{p}\right)}{2\left(\omega-c_{p}\right)(\theta-\omega \beta)}$. In $A_{1}^{R}$ it is obvious that we are subtracting a positive term $\alpha_{1} \theta \gamma \delta(\Delta-\phi-(1+\nu) g)$ from the numerator and adding another positive term $\gamma \delta(\Delta-\phi-(1+\nu) g)(\theta(1+v)-\beta \omega)(\theta(1+v)+\omega \beta)$ to the denominator. That is, the numerator gets smaller and the denominator gets larger. Given this and that the coefficient $(1+v)^{2}$ enters in both numerator and denominator, we conclude that $A_{1}^{R}<\hat{A}_{1}$. Since both price and output terms decrease in the quality, $p_{1}^{R}<\hat{p}_{1}$ and $q_{1}^{R}<\hat{q}_{1}$ should hold. In addition, we have the identical second period price, output, and quality under both Proposition 4 and Corollary 1. Therefore, when $R$ collects the used products prices, outputs, and qualities are weakly lower, compared to no a collection program.

\section{Proof of Proposition 6:}

Stage 4: The retailer $i$ chooses its output $q_{i 2}$ that optimizes its second period profit, given that market is in equilibrium: $\sum_{i} q_{i 2}=q_{2}=\alpha_{2}+\theta A_{2}-\beta p_{2}$.

$$
\max _{q_{i 2}} \pi_{i 2}=q_{i 2}\left(\left(\alpha_{2}+\theta A_{2}-\sum_{i} q_{i 2}\right) / \beta-\omega A_{2}\right)
$$

Assuming an interior solution, retailer $i$ 's output is

$q_{i 2}=\frac{\alpha_{2}+A_{2}(\theta-\beta \omega)}{(n+1)}, i=1,2,3, \ldots, n$. In equilibrium the outputs of the retailers are identical because they have the same marginal cost of production and face the same demand. Then the total output is $q_{2}=\frac{n \alpha_{2}+n A_{2}(\theta-\beta \omega)}{(n+1)}$ and the market price is $p_{2}=\frac{\alpha_{2}+A_{2}(\theta+n \beta \omega)}{(n+1) \beta}$ in period 2.

Note that when we plug $n=1$ into the above equations we obtain the same output and price expressions as in Proposition 1 with a single retailer.

Stage 3: $M$ optimizes its second period profit to choose the level of technology $A_{2}$, taking the retailers' reaction functions into account: 
$\max _{A_{2}} \pi_{M_{2}}=q_{2}\left(A_{2}, p_{2}\right)\left(\omega A_{2}-c_{p} A_{2}\right)-\mu A_{2}+r(.) q_{1}().(\Delta-g-\phi) A_{1}$.

The first order necessary condition yields

$A_{2}=\frac{(n+1) \mu-n \alpha_{2}\left(\omega-c_{p}\right)}{2 n\left(\omega-c_{p}\right)(\theta-\omega \beta)}$.

Plugging $A_{2}$ into $q_{2}$ and $p_{2}$ in stage 4 we obtain

$q_{2}=\frac{(n+1) \mu+n \alpha_{2}\left(\omega-c_{p}\right)}{2(n+1)\left(\omega-c_{p}\right)}$, and $p_{2}=\frac{(n+1) \mu(\theta+n \omega \beta)+n \alpha_{2}\left(\omega-c_{p}\right)(\theta-(2+n) \omega \beta)}{2 n(n+1) \beta\left(\omega-c_{p}\right)(\theta-\omega \beta)}$.

Note that some of the consumers choose to return the used products in the second period at the rate $r\left(A_{1}, p_{1}\right)=\gamma p_{1} / A_{1}$ to $M$.

Stage 2: Moving to the first period, every retailer chooses its output $q_{i 1}$ to maximize its sum of discounted profits. Namely,

$$
\left.\max _{q_{i 1}} \pi_{i 1}+\delta \pi_{i 2}=q_{i 1}\left(\left(\alpha_{1}+\theta A_{1}-\sum_{i} q_{i 1}\right) / \beta-\omega A_{1}\right)+\delta q_{i 2}\left(\left(\alpha_{2}+\theta A_{2}-\sum_{i} q_{i 2}\right) / \beta-\omega A_{2}\right)\right) .
$$

Taking the derivative with respect to $q_{i 1}$ yields

$q_{i 1}=\frac{\alpha_{1}+A_{1}(\theta-\beta \omega)}{(n+1)}, i=1,2,3, \ldots, n$.

The total output is $q_{1}=\frac{n \alpha_{1}+n A_{1}(\theta-\beta \omega)}{(n+1)}$ and the market price is $p_{1}=\frac{\alpha_{1}+A_{1}(\theta+n \beta \omega)}{(n+1) \beta}$ in period 1 , where the quality decision $A_{1}$ is determined in the first stage.

Stage 1: Since the first period decision impacts its first and second period profits, $M$ chooses $A_{1}$ by solving its aggregate profits in two periods. That is,

$$
\max _{A_{1}} \pi_{M_{1}}+\delta \pi_{M_{2}}=q_{1}\left(A_{1}, p_{1}\right)\left(\omega A_{1}-c_{p} A_{1}\right)-\mu A_{1}+\delta\left[q_{2}\left(A_{2}, p_{2}\right)\left(\omega A_{2}-c_{p} A_{2}\right)-\mu A_{2}+r\left(A_{1}, p_{1}\left(A_{1}\right)\right) q_{1}\left(A_{1}, p_{1}\left(A_{1}\right)\right)\left(\Delta A_{1}-\right.\right.
$$
$\left.\left.(\phi+g) A_{1}\right)\right]$.

Substituting $p_{1}\left(A_{1}\right), r\left(A_{1}\right)$, and $q_{1}\left(A_{1}\right)$ into the above maximization problem, the total profit expression becomes

$$
\begin{aligned}
& \pi_{M_{1}}+\delta \pi_{M_{2}}=\left(n \alpha_{1}+n \theta A_{1}-n \omega \beta A_{1}\right)\left(\omega A_{1}-c_{p} A_{1}\right) /(n+1)-\mu A_{1} \\
& +\delta\left[\left(n \alpha_{2}+n \theta A_{2}-n \omega \beta A_{2}\right)\left(\omega A_{2}-c_{p} A_{2}\right) /(n+1)-\mu A_{2}+\gamma\left(\alpha_{1}+\theta A_{1}+n \omega \beta A_{1}\right)(\Delta-\phi-g) n\left(\alpha_{1}+\theta A_{1}-\right.\right.
\end{aligned}
$$

$\left.\left.\omega \beta A_{1}\right) /(n+1)^{2} \beta\right]$

The first order condition for the profit maximization with respect to $A_{1}$ results in

$$
A_{1}=\frac{(n+1)^{2} \beta \mu-n \alpha_{1}\left[\beta(n+1)\left(\omega-c_{p}\right)+\gamma \delta(\Delta-\phi-g)(2 \theta-\beta \omega(1+n))\right]}{2 n(\theta-\omega \beta)\left[\beta\left(\omega-c_{p}\right)(n+1)+\gamma \delta(\Delta-\phi-g)(\theta+n \omega \beta)\right]} .
$$

Plugging the above $A_{1}$ back into $p_{1}\left(A_{1}\right), q_{1}($.$) , and r($.$) we obtain equilibrium price and quantity in$ period 1, and the collection rate as functions of the model parameters. Therefore, we obtain the results as in Proposition 6.

\section{Proof of Proposition 8:}

Assuming an interior solution, the retailer $i$ 's output is

$$
q_{i 2}=\frac{\alpha_{2}+A_{2}(\theta-\beta \omega)}{(n+1)}, i=1,2,3, \ldots, n \text {. In equilibrium the outputs of the retailers are identical because }
$$


they have the same marginal cost of production and face the same demand. Then the total output is $q_{2}=\frac{n \alpha_{2}+n A_{2}(\theta-\beta \omega)}{(n+1)}$ and the market price is $p_{2}=\frac{\alpha_{2}+A_{2}(\theta+n \beta \omega)}{(n+1) \beta}$ in period 2.

Note that when we plug $n=1$ ( and the value of $A_{2}$ below) into the above equations we will obtain the same output and price as in Proposition 4 for a single retailer.

Stage 3: $M$ optimizes its second period profit to choose the level of technology $A_{2}$, taking the retailers' reaction functions into account:

$\max _{A_{2}} \pi_{M_{2}}=q_{2}\left(A_{2}, p_{2}\right)\left(\omega A_{2}-c_{p} A_{2}\right)-\mu A_{2}+r(.) q_{1}().(\Delta-g(1+\nu)-\phi) A_{1}$.

The first order necessary condition yields

$A_{2}=\frac{(n+1) \mu-n \alpha_{2}\left(\omega-c_{p}\right)}{2 n\left(\omega-c_{p}\right)(\theta-\omega \beta)}$.

Plugging $A_{2}$ into $q_{2}$ and $p_{2}$ we obtain

$q_{2}=\frac{(n+1) \mu+n \alpha_{2}\left(\omega-c_{p}\right)}{2(n+1)\left(\omega-c_{p}\right)}$, and $p_{2}=\frac{(n+1) \mu(\theta+n \omega \beta)+n \alpha_{2}\left(\omega-c_{p}\right)(\theta-(2+n) \omega \beta)}{2 n(n+1) \beta\left(\omega-c_{p}\right)(\theta-\omega \beta)}$.

Stage 2: Moving to the first period, every retailer chooses its output $q_{i 1}$ to maximize its sum of discounted profits. Namely,

$\max _{q_{i 1}} \pi_{i 1}+\delta \pi_{i 2}=q_{i 1}\left(\left(\alpha_{1}+\theta A_{1}-\sum_{i} q_{i 1}\right) / \beta-\omega A_{1}\right)+\delta\left[q_{i 2}\left(\left(\alpha_{2}+\theta A_{2}-\sum_{i} q_{i 2}\right) / \beta-\omega A_{2}\right)+r(.) q_{1}(.) \nu g A_{1} / n\right]$.

Taking the derivative with respect to $q_{i 1}$ yields

$q_{i 1}=\frac{\alpha_{1}(n+v)+(\theta(n+v)-n \beta \omega) A_{1}}{n((n+1)+2 v)}, i=1,2,3, \ldots, n$.

where $v=\delta \gamma g \nu$ and

the total output becomes $q_{1}\left(A_{1}\right)=\frac{\alpha_{1}(n+v)+(\theta(n+v)-n \beta \omega) A_{1}}{n+1+2 v}$ and the market price gets $p_{1}=$ $\frac{\alpha_{1}(1+v)+A_{1}(\theta(1+v)+n \beta \omega)}{(n+1+2 v) \beta}$ in period 1, where the quality decision $A_{1}$ will be determined in the first stage. Observe that if we plug $n=1$, the price and the output decisions boil down to the ones obtained in Proposition 4 for one retailer case.

Stage 1: $M$ chooses $A_{1}$ by solving its aggregate profits in two periods. That is, $\max _{A_{1}} \pi_{M_{1}}+\delta \pi_{M_{2}}=q_{1}\left(A_{1}, p_{1}\right)\left(\omega A_{1}-c_{p} A_{1}\right)-\mu A_{1}+\delta\left[q_{2}\left(A_{2}, p_{2}\right)\left(\omega A_{2}-c_{p} A_{2}\right)-\mu A_{2}+r\left(A_{1}, p_{1}\left(A_{1}\right)\right) q_{1}\left(A_{1}, p_{1}\left(A_{1}\right)\right)\left(\Delta A_{1}-\right.\right.$ $\left.\left.(\phi+g(1+\nu)) A_{1}\right)\right]$

Substituting $p_{1}\left(A_{1}\right), r\left(A_{1}\right)$, and $q_{1}\left(A_{1}\right)$ into the above maximization problem, and taking the derivative of the total discounted profit results in

$A_{1}=\frac{(n+1+2 v) \beta\left[\mu(n+1+2 v)-\alpha_{1}(n+v)\left(\omega-c_{p}\right)\right]-\alpha_{1} \tilde{\Delta}[2 \theta(1+v)(n+v)+n(n-1) \beta \omega]}{2 \tilde{\Delta}(\theta(1+v)+n \omega \beta)(\theta(n+v)-n \omega \beta)+2 \beta\left(\omega-c_{p}\right)(n+1+2 v)(\theta(n+v)-n \omega \beta)}$,

where $\tilde{\Delta}=\delta \gamma(\Delta-\phi-(1+\nu) g)$.

Plugging $A_{1}$ back into $p_{1}\left(A_{1}\right), q_{1}($.$) , and r($.$) the subgame perfect Stackelberg equilibrium price and$ output, and the collection rate are obtained as functions of model parameters. 


\section{References}

[1] Andriolo, A., Battini, D., Persona, A., and Sgarbossa, F. (2015). Haulage sharing approach to achieve sustainability in material purchasing: New method and numerical applications. International Journal of Production Economics, 164, 308-318.

[2] Atasu, A., V. D. R. Guide, L.N. Van Wassenhove. 2008a. Product reuse economics in closed-loop supply chain research. Production and Operations Management. 17, 483-497.

[3] Atasu A. and Çetinkaya, S. (2006). Lot Sizing for Optimal Collection and Use of Remanufacturable Products over a Finite Life Cycle. Production and Operations Management, 15:4, 473-487.

[4] Atasu, A., M. Sarvary, L.N. Van Wassenhove. 2008b. Remanufacturing as a marketing strategy. Management Science. 54, 1731-46.

[5] Bernstein, F., F. Chen, A. Federgruen. 2002. VMI and supply chain coordination: The case of one supplier and competing retailers. Working paper series, Fuqua School of Management, Duke University, Durham, NC.

[6] Bernstein, F., A. Federgruen. 2005. Decentralized supply chains with competing retailers under demand uncertainty. Management Science. 51 18-29.

[7] Chen, F., A. Federgruen, Y. Zheng. 2001. Coordination mechanisms for a distribution system with one supplier and multiple retailers. Management Science. 47 693-708.

[8] Cipriano F. and Filippini R. 1998. TQM impact on quality conformance and customer satisfaction: A causal model. International Journal of Production Economics, 55, 1-20.

[9] De Giovanni, P. 2011. Quality improvement vs. Advertising support: which strategy works better for a manufacturer? European Journal of Operational Research. 208, 119-130.

[10] De Giovanni, P., and Esposito Vinzi, V., 2012. Covariance versus component-based estimations of performance in green supply chain management. International Journal of Production Economics, 135, 907-916.

[11] De Giovanni, P. 2013. Should a retailer support a quality improvements strategy? Annals of the International Society of Dynamic Games, Birkhauser, 125-148.

[12] De Giovanni, P. 2014. Environmental collaboration through a reverse revenue sharing contract. Annals of Operations Research, 6, 1-23. 
[13] De Giovanni, P., G. Zaccour. 2013. Cost-revenue sharing in a closed loop supply chain. Annals of the International Society of Dynamic Games.

[14] De Giovanni, P. and Zaccour, G. 2014. A two period game of Closed-loop supply chain. European Journal of Operational Research, 232(1), 22- 40.

[15] De Giovanni, P. 2015. State- and Control-dependent incentives in a Closed-loop supply chain with dynamic returns. Dynamic Games and Applications, 1(4), 1-35.

[16] De Giovanni, P., Puduru, V. and Zaccour, G. 2016. Incentive Strategies for an Optimal Recovery Program in a Closed-Loop Supply Chain, European Journal of Operational Research, 249(2), 605-617.

[17] Debo, L. G., Tokay, L.B., Van Wassenhove, L. N. 2005. Market segmentation and Product Technology Selection for Remanufacturable Products. Management Science, 51(8), 1193-205.

[18] El Ouardighi, F. 2014. Supply Quality Management with optimal wholesale price and reveneu sharing contracts: A two-stage game approach. International Journal of Production Economics, 156(2), 260-268.

[19] El Ouadighi, F. and Kim, B. 2012. Supply quality management with wholesale price and revenue-sharing contract under horizontal competition, European Journal of Operational Research, 206(2), p. 329-340

[20] Ferguson ME, LB Tokay. 2006 The effect of competition on recovery strategies. Production and Operations Management 15:351-368

[21] Ferrer, G., J.M. Swaminathan. 2006. Managing new and remanufactured products. Management Science, $52(1), 15-26$.

[22] Fleischmann, M., Krikke, H.R., Dekker, R., Flapper, S.D.P. 2000. A characterisation of logistics networks for product. Omega: The International Journal of Management Science, 28(6), 653-666.

[23] Fleischmann, M., van Nunen, J., Grave, B. 2003. Integrating closed-loop supply chains and spare parts in IBM. Interface, 33(6), 44-56.

[24] Geyer, R., L.N. Van Wassenhove., Atasu, A. 2007. The economics of remanufacturing under limited component durability and finite product life cycles. Management Science, 53(1), 88-10.

[25] Ghosh, D. and Shah, J. (2015). Supply chain analysis under green sensitive consumer demand and cost sharing contract. International Journal of Production Economics, 164, 319-329.

[26] Glock C.H. and Kim, T. (2015). The effect of forward integration on a single-vendor-multi-retailer supply chain under retailer competition. International Journal of Production Economics, 164, 179-192. 
[27] Guide, Jr, V.D.R. 2000. Production planning and control for remanufacturing: Industry practice and research needs. Journal of Operations Management, 18(4), 467-483.

[28] Guide, V.D.R., L.N. Van Wassenhove. 2009. The evolution of closed-loop supply chain research. Operations Research, 57(1), 10-18.

[29] Hammnod, D. and Beullens, P. (2007). Closed-loop supply chain network equilibrium under legislation, European Journal of Operations Research, 183(2), 895-908.

[30] Kaynak, H. (2003). The relationship between total quality management practices and their effects on firm performance. Journal of Operations Management, 21, 405-435.

[31] Kenne, J.P., Dejax, P. and Charbi, A. 2012. Production planning of a hybrid manufacturingremanufacturing system under uncertainty within a closed-loop supply chain, International Journal of Production Economics, 135, 81-93.

[32] Kumar, S. and Putnam, V. (2008). Cradle to cradle: Reverse logistics strategies and opportunities across three industry sectors, International Journal of Production Economics, 115(2), 305-15.

[33] Majumder, P. and Groenevelt, H. (2001) Competition in remanufacturing. Production and Operations Management, 10, 125-141.

[34] Nair A, Narasimhan N (2006) Dynamics of competing with quality- and advertising-based customers' greenness. European Journal of Operational Research 175:462-474.

[35] Ostlin, J., Sundin, E. and Bjorkman, M. (2008). Importance of closed-loop supply chain relationships for product remanufacturing. International Journal of Production Economics, 115, 336-348.

[36] Savaskan, R.C., Bhattacharya, S., Van Wassenhove, L.N. (2004). Closed loop supply chain models with product remanufacturing. Management Science, 50(2), 239-252.

[37] Savaskan, R.C., Van Wassenhove, L.N. (2006). Reverse Channel Design: The Case of Competing Retailers. Management Science, 52(1), 1-14.

[38] Sluis, S. and De Giovanni, P. (2016). The selection of contracts in supply chains: an empirical analysis, Journal of Operations Management, 41(1), p. 1-11.

[39] Souza, G.C. (2013). Closed-Loop Supply Chains: A Critical Review, and Future Research, Decision Sciences, 44(1), 7-38. 